\title{
Post-tensioned ceramic structures: design, analysis and prototyping
}

\author{
Martin Bechthold ${ }^{1} \cdot$ Zach Seibold $^{1}\left(\mathbb{D} \cdot\right.$ Saurabh Mhatre ${ }^{1}(\mathbb{C}$
}

Received: 30 October 2021 / Accepted: 25 January 2022 /Published online: 21 February 2022

(c) The Author(s), under exclusive licence to Springer Nature Switzerland AG 2022

\begin{abstract}
This research reports on numerical and experimental methods for the use of post-tensioning with brittle ceramic extrusions. It proposes a novel construction approach, including new joint typologies, and demonstrates the viability of ceramic as a primary structural material in a bending-active context through two pavilion-scale prototypes. The research proceeded in three distinct phases. First, relevant material properties — compressive strength, bending strength, modulus — were determined experimentally. Next, several post-tensioned beam prototypes were tested to examine the interaction between post-tensioning steel and ceramic, understand failure modes, and refine construction details. Finally, two post-tensioned prototypes were designed based on these findings, the Vierendeel Arch and the Hypar Tower. The design process for each prototype involved a novel digital workflow that utilized multiple parametric models to generate and analyze global design geometry, link to structural analysis software, discretize the forms into components based on available stock sizes, accommodate for assembly tolerances, and generate component cut lists. The prototypes behaved as predicted, demonstrating that post-tensioning can successfully control bending stresses in ceramic extrusions, and introducing entirely new applications for the material.
\end{abstract}

Keywords Structural ceramics $\cdot$ Post-tensioning $\cdot$ Prototype $\cdot$ Ceramic extrusion

\section{Introduction}

Since the invention of prestressing by Eugène Freyssinet in 1928 [1] the engineering community seems to have largely forgotten that the application of an internal compression force can imbue impressive structural capacities not just for concrete, but for any material that is strong in compression and weak in tension. There have been occasional applications of post-tensioning in natural stone or brick structures, certainly much enthusiasm about prestressing in tempered glass, but thin-walled ceramics have been largely neglected in this effort. Despite increased interest in using ceramic claddings and surface finishes in architecture, structural applications for the material remain rare [2]. The reasons

Martin Bechthold and Zach Seibold contributed equally to the work presented in this manuscript.

Martin Bechthold

mbechthold@gsd.harvard.edu

$\triangle$ Zach Seibold

zseibold@gsd.harvard.edu

1 Material Processes and Systems (MaP+S) Group, Harvard University Graduate School of Design, 48 Quincy Street, Cambridge, MA 02138, USA lie at least partially in deep-seated industry cultures in which ceramic tile producers are focused on finishes and cladding, while the ceramic brick industry provides structural materials. Production cultures in the brick and the ceramic tile industry are radically different, and the significant advances in control and accuracy of tile production remain uncommon for brick manufacturing, with few exceptions such as the highly perforated and insulating bricks common in European construction [3]. Yet ceramic's durability, ease of maintenance, high compressive strength, and the availability of a myriad of finishes are advantages compared to competing material systems like metal, concrete, glass, wood, stone, or polymers/composites. Among ceramic's disadvantages, however, are brittleness and the lack of tensile and bending strength.

Ceramic tiles have demonstrated lifespans of over 100 years on the facades of buildings, but as structures are adapted to other uses, few facades or interior finishes remain in service for this extended interval, thus frequently rendering perfectly serviceable tiles obsolete. Of all building components it is the structure that remains in place and untouched the longest, providing the incentive for investigating how we might expand the applications of ceramic 
Fig. 1 Images of the completed prototypical structures - the (a) Vierendeel Arch Prototype and the (b) Hypar Tower (photo credit Jordi Font de Mora)

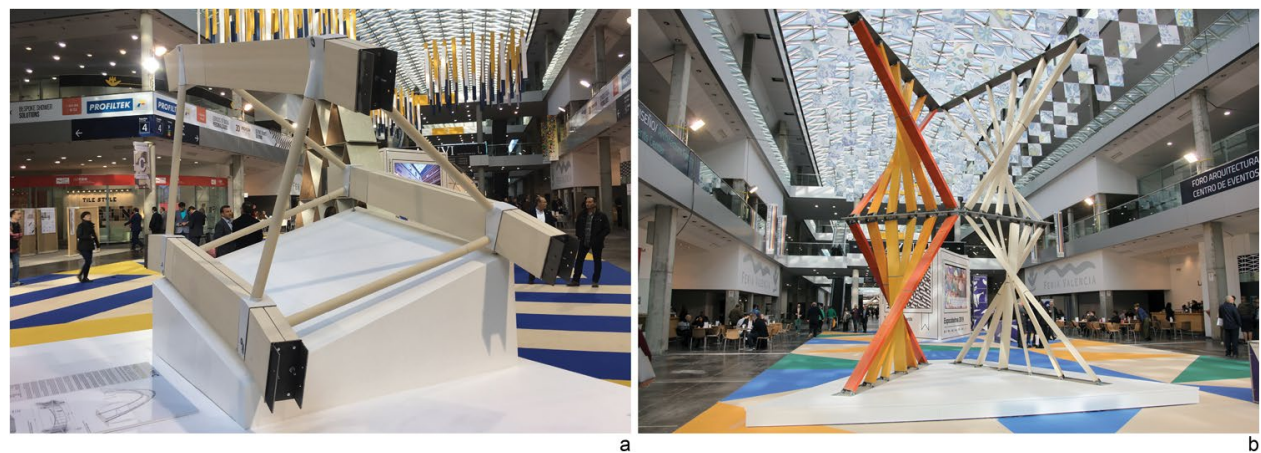

extrusion beyond surface finishes into structural components where longevity is a primary concern [4].

The present study presents the requirements and capabilities of structural, thin-walled ceramics, with a focus on post-tensioning as the most promising strategy to address the mechanical properties of the material. ${ }^{1}$ The research reports a method for internally post-tensioning hollow ceramic extrusions to increase their capabilities in bending, thus creating new design opportunities, including the possibility to realize cantilevers, floor slabs, or even beam bridges - all systems that can benefit from the excellent fire-resistance, longevity, and the economy of customized industrial ceramic production. Methodologically we report experimental work on post-tensioned ceramic extrusions in the laboratory, which allows a discussion of failure modes and other material-specific challenges. As a proof of concept, two small prototypical structures were designed and realized (Fig. 1), demonstrating that ceramic beams of medium span are indeed viable despite the material's lack of bending strength.

\section{Background}

\section{Ceramic extrusions}

Ceramic has recently gained renewed interest in architectural research and practice, fueled by an interest in durable and hence sustainable material choices and the ability to customize forms, formats and finishes relatively easily [5]. Much of the academic research has focused on part customization via a range of production methods including robotic tile placement [6], slip-casting [7], and, most actively, additive manufacturing [8-11]. But despite a plethora of creative research

\footnotetext{
1 We will use the term post-tensioning for the work presented here, since the forces in the tendon are induced after the assembly of the member, much as in concrete systems with unbonded tendons. Mechanically speaking prestressing and post-tensioning can have very similar effects.
}

the industry continues to do what it has long excelled at - the high-volume production of dry-pressed or extruded tiles at an industrial scale [5].

Ceramic extrusions are produced on industrial equipment that consists of auger-driven extruders which force clay through the extrusion die and onto a conveyor belt [12]. The extrusions can be solid in cross-section - such as bricks - or else are hollow or open profiles. The process is particularly well suited to the medium to high-volume production of linear elements at a competitive cost [5]. Wall thicknesses for thin-walled elements start at around $8 \mathrm{~mm}$, and typical element length ranges from $0.5-2 \mathrm{~m}$. The extruded clay profiles are cut to smaller lengths as required, either immediately after extrusion or after firing. The latter method gives the most precise results and yields dimensional tolerances in the range of millimeters. Previous work by the Material Processes and Systems Group $(\mathrm{MaP}+\mathrm{S})$ [13] and others [14] demonstrated the design affordances of custom extrusion profiles when further individualized through cuts at variable angles. These studies leveraged the integration of computational tools with computer numerically controlled (CNC) ceramic production processes, but shy away from pursuing more demanding structural applications and instead rely on the stacking of similar elements to create partitionscale wall assemblies.

\section{Structural ceramic tiles}

The structural use of ceramic tile has been demonstrated in funicular compression structures, leveraging the significant compressive strength of the material [15]. Yet the use of extremely thin, large format tile elements inherently increases the risk of brittle failures during construction or use. Funicular structural systems (e.g., arches, vaults, grid shells) not only pose challenges for the use of linear tile elements, they also remain relatively rare in contemporary architectural practice. The vast majority of small- to medium span building structures rely on bending-active approaches, a context in which ceramic is not considered viable due to its brittle failure behavior and lack of bending strength. 
Fig. 2 Image of (a) compression test setup and (b) three-point bending test setup
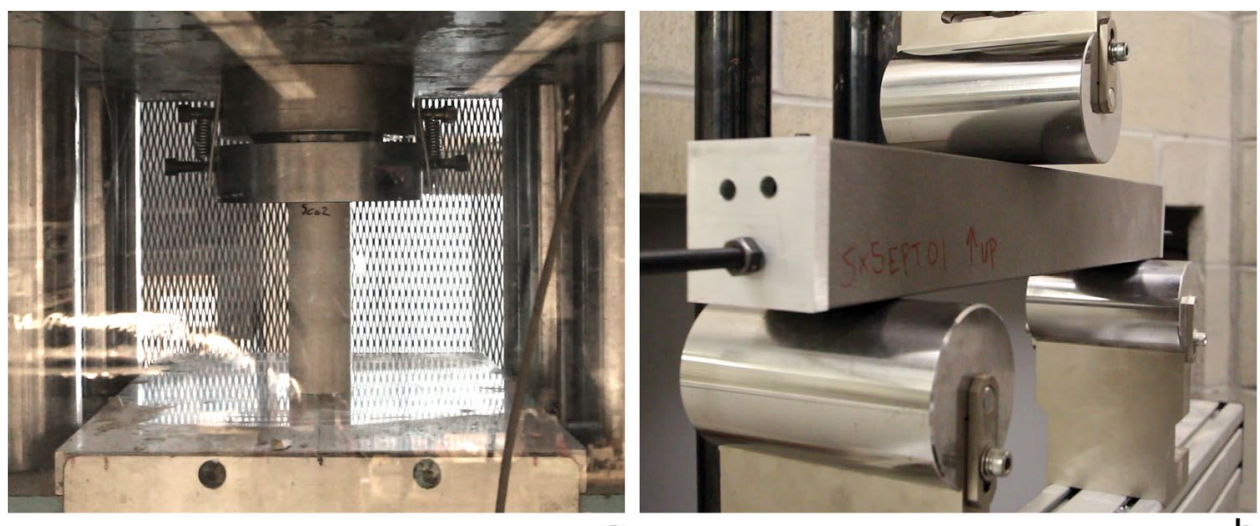

Reinforcing the ceramic system has only received scant attention, with research of reinforced masonry focusing on special problems such as seismic resistance or dynamic behavior [16]. Work on thin-walled reinforced ceramics has been limited to largely qualitative design experiments without mechanical testing [17]. Historically, Eladio Dieste's work on tile shells and vaults provides the most impressive precedent for demonstrating the structural potential of the material. Dieste engineered and built numerous beam-like shells made from what he referred to as "cerámica armada", or reinforced ceramic tiles. His approach involved a layer of relatively thick $(2-3 \mathrm{~cm})$ ceramic tiles on the underside fitted with a mortar material to fill in the joints, a post-tensioning system of hooks and steel cables that interlocked with the tiles, and a thin concrete upper layer that provided weatherproofing and structural continuity. Post-tensioning systems by Dieste ensured that the tiles were only subject to compression and shearing, avoiding tensile and bending stresses [18] . These structures have stood the test of time for over 50 years or more and remain stable and safe today. More recent examples of post-tensioned ceramics have utilized thin ceramic tiles to create self-supporting vertical ceramic assemblies at the architectural scale [19], however no examples are known for beam-like elements.

\section{Post-tensioned masonry beams}

The fundamental mechanics of post-tensioned beams are well understood [20], but few existing studies have investigated post-tensioning for flat, beam-like structural systems using ceramic elements. In the 1930's, Anderegg conducted tests of ceramic masonry units as components in prestressed beams and columns [21]. Post-tensioned ceramic slabs [22] and domes [23] were briefly investigated in the middle of the twentieth century, but have not received much attention since. Johnston, et al. demonstrated that a ceramic slab prestressed at $9.31 \mathrm{MPa}$ and spanning $2.74 \mathrm{~m}$ could support a truck. Vertical post-tensioning has been deployed with the goal of improving the seismic resistance of brick walls [16], or to improve longevity and reduce cracking for veneer brick walls [24]. None of these studies have investigated highquality, industrial extrusions as the compression material in the post-tensioning system. Two studies at the TU Graz demonstrated that thin ceramic extrusions, when post-tensioned, can be used as structural beams. These proof of concepts, however, did not provide any quantitative data on the mechanical behavior [17, 25]. In summary, there is a persistent lack of understanding around the mechanical behavior and detailing of post-tensioning thin-walled ceramics.

\section{Methods}

Since ceramic extrusions are not typically used as primary structural elements little data is available on their relevant mechanical properties. One manufacturer reports the modulus of rupture as $17 \mathrm{~N} / \mathrm{mm} .{ }^{2}$ Compressive strength data is not generally available since it is not relevant for facades or floor tiles. Structural safety factors are also unknown. A series of tests was carried out to determine the fundamental mechanical properties needed to design a post-tensioning system based on standard industrial extrusions (Fig. 2). The ceramic extrusion profiles utilized for the tests were production surplus, shipped to the United States by a Spanish producer.

\section{Compression tests}

Compression tests were conducted using unreinforced ceramic extrusions. A total of 15 extrusions were tested, as described in Table 1.

\footnotetext{
${ }^{2}$ Unpublished data provided by Cerámica Mayor S.A. via email 5/25/2018
} 
Table 1 Ceramic Extrusion Compression Test Specimen Parameters

\begin{tabular}{llllll}
\hline Quantity & $\begin{array}{l}\text { Cross Section } \\
\text { Dimensions }(\mathrm{mm})\end{array}$ & Cross Section & $\begin{array}{l}\text { Wall Thick- } \\
\text { ness }(\mathrm{mm})\end{array}$ & $\begin{array}{l}\text { Cross Sectional } \\
\text { Area }\left(\mathrm{mm}^{2}\right)\end{array}$ & Height (mm) \\
\hline 5 & $50 \times 50$ & Square & 9.6 & 1569 & 150 \\
6 & $50 \varnothing$ & Circular & 8.5 & 1116 & 150 \\
4 & $50 \times 130$ & Rectangular & 9.7 & 3758 & 180 \\
\hline
\end{tabular}

Fig. 3 Still video frames showing compression test specimen before application of load (left column) and immediately before failure (right column); (a) specimen with high bearing capacity exhibited vertical columnar cracking while (b) specimen with low bearing capacity exhibited flaking at the edge of the bearing surface. Red arrows and dashed lines indicate areas of interest
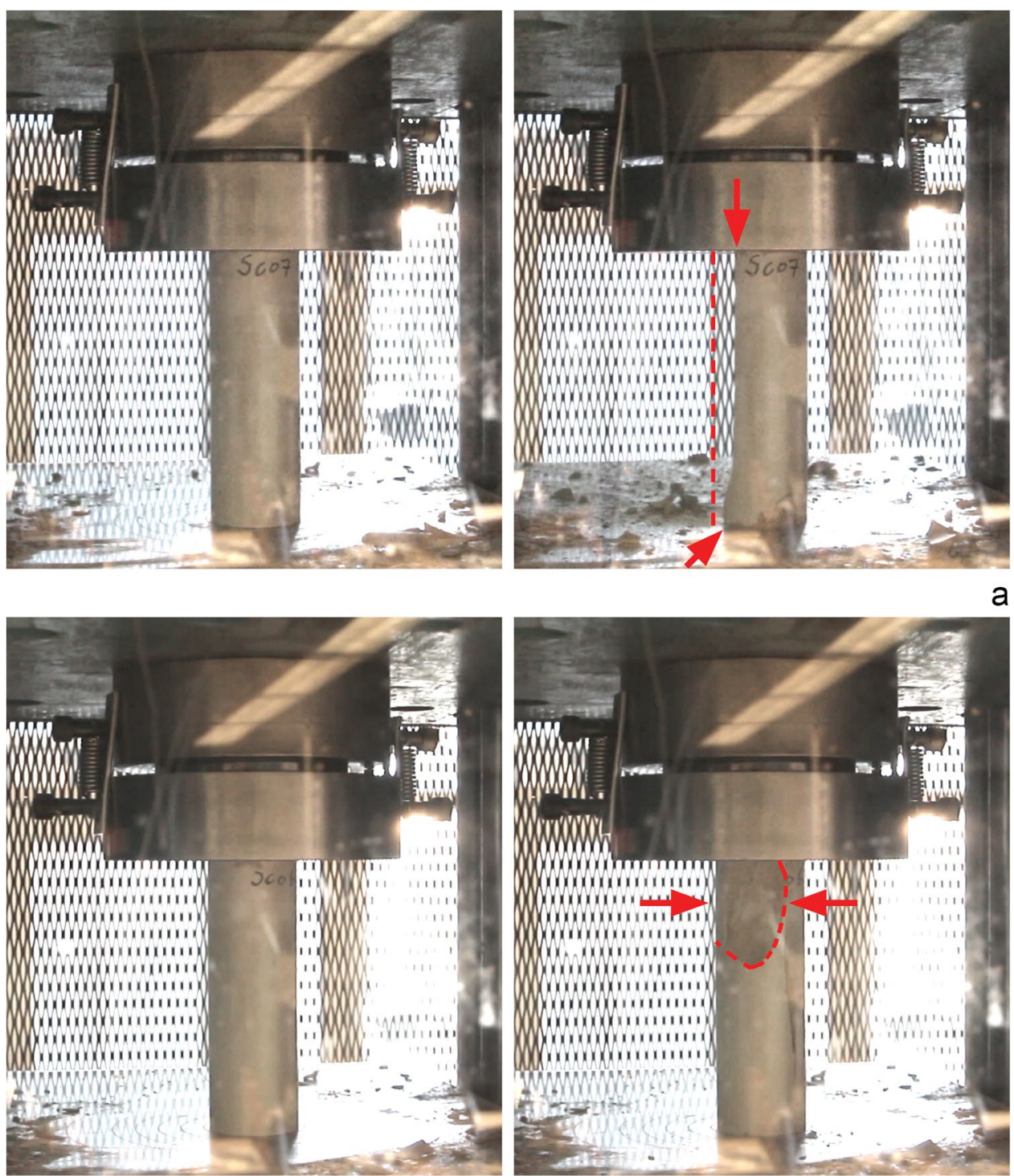

a

Compression tests were performed on a Forney compression machine with a capacity of $2669 \mathrm{kN}$. One bearing surface of each specimen was ground parallel with the other using a Matest Model C299 automatic grinding machine. Load was applied to specimen at a rate of $0.517 \mathrm{MPa}$ per second. Ultimate compressive strength of all specimen tested varied from 51.6-281.7 MPa, however this variation is likely a result of localized stress concentrations in the specimen due to small imperfections at their bearing surfaces. Video documentation of the tests shows that specimen with lower bearing capacity generally exhibited flaking at the edges of the bearing surface in the moments prior to failure, consistent with the presence of localized stress concentrations, while specimen with a higher capacity did not exhibit the same degree of cracking at the edges and instead showed evidence of columnar 


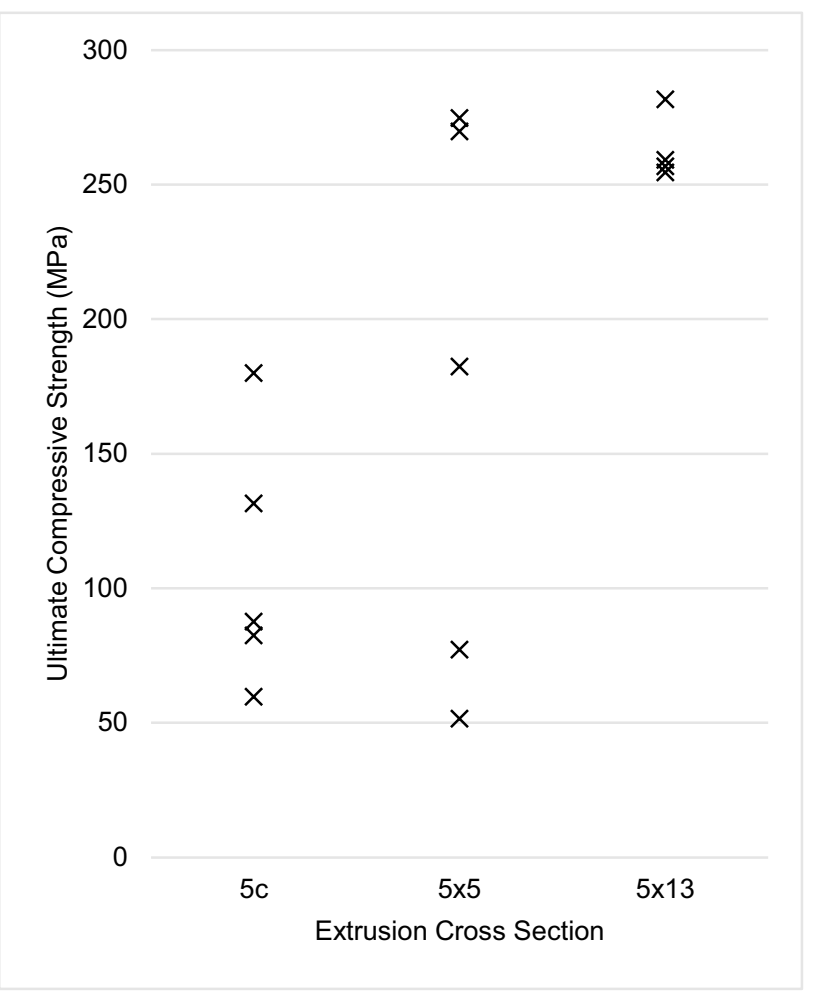

Fig. 4 Scatter plot showing results of compressive strength tests

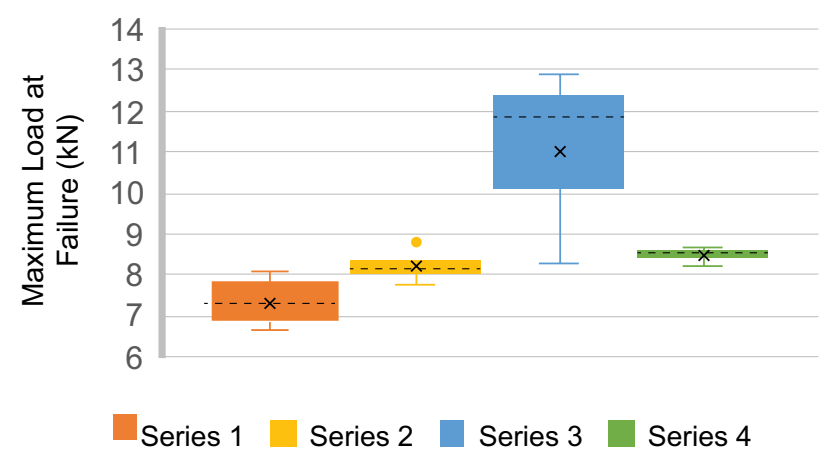

Fig. 5 Box plot showing average load at failure (marked with an " $\mathrm{x}$ ") in $\mathrm{kN}$ for three-point bending tests, inclusive median (marked with a dashed line) and standard deviation for each test series, including unreinforced (Series 1), concentrically post-tensioned (Series 2), eccentrically post-tensioned (Series 3 ) and concentrically post-tensioned with epoxy (Series 4) extrusions

vertical cracking at failure (Fig. 3). The specimen that did not exhibit a failure mode consistent with localized stress concentrations (6 samples total) had an average ultimate compressive strength of $266 \mathrm{MPa}$ (standard deviation 11.0 MPa) (Fig. 4). This is easily twice as much as some of the best fired clay bricks used in construction today, and about 5-6 times the compressive strength of commonly used fired clay bricks [26].

\section{Three-point bending tests - Small specimen}

A series of three-point bending tests were conducted on several different ceramic extrusions, included unreinforced extrusions and several post-tensioned assemblies (Fig. 5). All extrusions were square in cross section measuring $50 \mathrm{~mm}$ per side with a wall thickness of $9.6 \mathrm{~mm}$. All tests were carried out on a SATEC three-point bending machine with a maximum load capacity of $267 \mathrm{KN}$. All samples were tested as single beam sections with a span of $300 \mathrm{~mm}$ between supports and the load applied at midspan.

\section{Unreinforced extrusions}

A total of 4 unreinforced samples were tested (Series 1). The maximum load at failure averaged $7.3 \mathrm{kN}$ with a standard deviation of $0.657 \mathrm{kN}$. The lowest value was $6.7 \mathrm{kN}$. The resulting maximum bending strength was an average value of $29 \mathrm{MPa}$. The modulus of rupture had an average value of 11,295 MPa. The bending strength was $70 \%$ higher than reported by the manufacturer $(17 \mathrm{MPa})$.

\section{Post-tensioned extrusions}

Additional three-point bending tests using post-tensioned extrusions were conducted using the same extrusion profiles as described above. The post-tensioning force was applied by a threaded steel rod measuring $6.35 \mathrm{~mm}$ in diameter with a tensile strength of $1034.2 \mathrm{MPa}$. Aluminum endcaps $6.35 \mathrm{~mm}$ in thickness distributed post-tensioning forces to the ends of the ceramic extrusions. A hole drilled in the endcaps registered the steel rod within the ceramic extrusion. Conical spring washers were used to determine the amount of post-tensioning - these washers deform to a flattened state when bolts placed at either end of the rod were tightened to a prescribed tensile force.

3 samples were tested with a concentric post-tensioning force of $6 \mathrm{kN}$ (Series 2). The average load at failure was $8.29 \mathrm{kN}$ (compared to $7.3 \mathrm{kN}$ without post-tensioning). The equivalent bending stress at fracture was $33.4 \mathrm{MPa}$ (standard deviation 1.7 MPa), the Equivalent Young's Modulus at fracture averaged 13,666.0 $\mathrm{MPa}$ (standard deviation 2172.2 MPa).

3 samples were tested with an eccentric post-tensioning force of $6 \mathrm{kN}$ (Series 3). The post-tensioning rod was located toward the bottom of the ceramic cross section, at an eccentricity e $=10.2 \mathrm{~mm}$ from the neutral axis. The average load at failure was $10.9 \mathrm{kN}$ (compared to $8.29 \mathrm{kN}$ with concentric post-tensioning). The equivalent bending stress at fracture was $45.8 \mathrm{MPa}$ (standard deviation 7.9 MPa), the Equivalent Young's Modulus at fracture averaged 18,714.4 MPa (standard deviation 1344.5 MPa). Of the six specimen tested in series 2 and 3, four failed in tension at mid span while two 


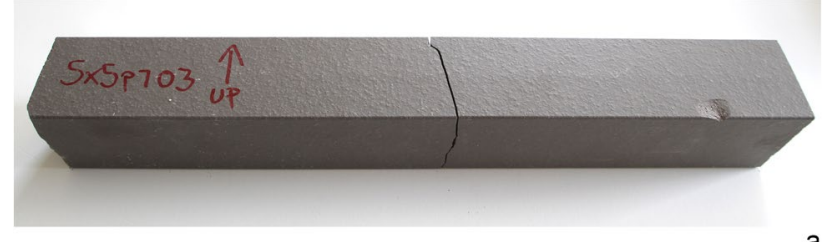

a

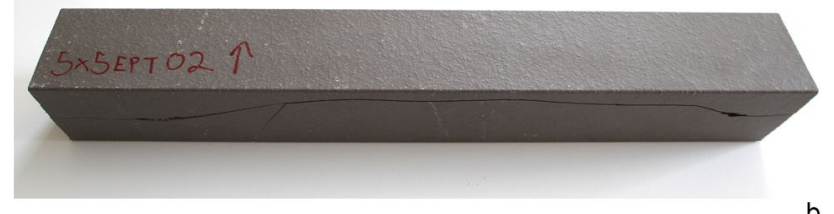

b

Fig. 6 Images showing typical failure modes of three-point bending tests (a) in tension at mid span and (b) via shear cracking industrially manufactured in Spain and shipped to the United States, at a scale similar to applications in buildings. The interest was in bending, buckling behavior as well as in prototyping various connection details. Three different beam types were tested (Fig. 7). All were made from the same structural shape measuring $5 \times 13 \mathrm{~cm}$ in cross section. Relevant area properties are listed in Table 2 . These properties were derived from a Rhino model but confirmed through measurements. Two specimens were weighed to derive their self-weight. A self-weight of $0.0832 \mathrm{~N} / \mathrm{mm}$ was derived.

\section{Beam types}

Beam A The beam consisted of three segments, connected with metal plates fitted with shear dowels. All metal plates

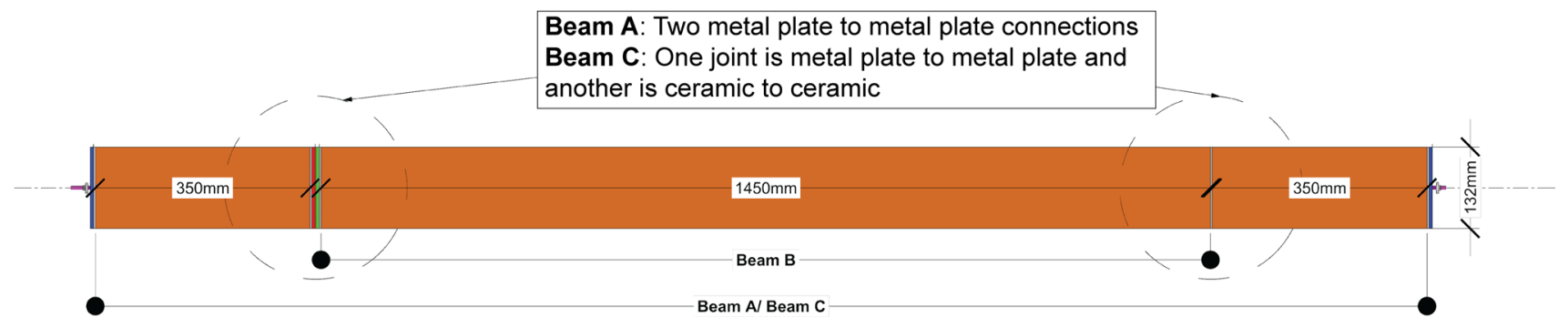

Fig. 7 Image showing construction-scale beam types

failed via shear cracking consistent with the lines of principal stresses in beams (Fig. 6).

A fourth set of specimens were tested, again with a concentric post-tensioning setup identical to series 2 . To avoid possible stress concentration between the metal end caps and the slightly uneven surfaces of the extrusions at the end, a thin layer of epoxy was applied between metal and ceramic (Series 4). The post-tensioning force was the same as in series 2 and $3(6 \mathrm{kN})$. The series 4 specimens failed at an average load of $8.53 \mathrm{kN}$ (compared to $8.29 \mathrm{kN}$ with concentric post-tensioning). Apart from a slight increase in the force at failure the most significant improvement of series 4 over series 2 was that all samples failed in tension at midspan, and standard deviation of failure loads was reduced significantly from $0.4 \mathrm{kN}$ for series 2 to $0.11 \mathrm{kN}$ for series 4 . Clearly a main concern in detailing these beams is the uniform application of post-tensioning to avoid stress concentrations.

\section{Three-point bending test - Construction-size specimen}

The objective of these tests was to determine the load-bearing characteristics of post-tensioned ceramic extrusions,
Table 2 Ceramic extrusion cross section properties

\begin{tabular}{lllll}
\hline Cross Section & Depth $(\mathrm{mm})$ & Area $\left(\mathrm{mm}^{2}\right)$ & $\begin{array}{l}\text { Section } \\
\text { Modulus } \\
(\mathrm{I} / \mathrm{y})\left(\mathrm{mm}^{3}\right)\end{array}$ & $\begin{array}{l}\text { Moment } \\
\text { of Inertia } \\
\left(\mathrm{mm}^{4}\right)\end{array}$ \\
\hline $\begin{array}{l}5 \mathrm{~cm} \times 13 \mathrm{~cm} \\
\text { Rect. }\end{array}$ & 50 & 3750 & 94,389 & $6,071,667$ \\
\hline
\end{tabular}

were bonded to the ceramic using high-strength epoxy, rated at $69 \mathrm{MPa}$ compressive strength. A medium strength stainless steel post-tensioning rod with $6.4 \mathrm{~mm}$ diameter and yield strength of $30.2 \mathrm{kN}$ was used to induce the axial compressive stress. The tension was induced through a torque wrench and ranged between $2.3-8.77 \mathrm{kN}$. The span was $2140 \mathrm{~mm}$.

Beam B This beam was the middle segment of beam A, thus a simple ceramic extrusion without the added-on end pieces. Post-tensioning system and forces were the same as for A. The span was $1365 \mathrm{~mm}$.

Beam B1 and B2 These beams were identical in cross-section and span to beam B but had no post-tensioning element. 


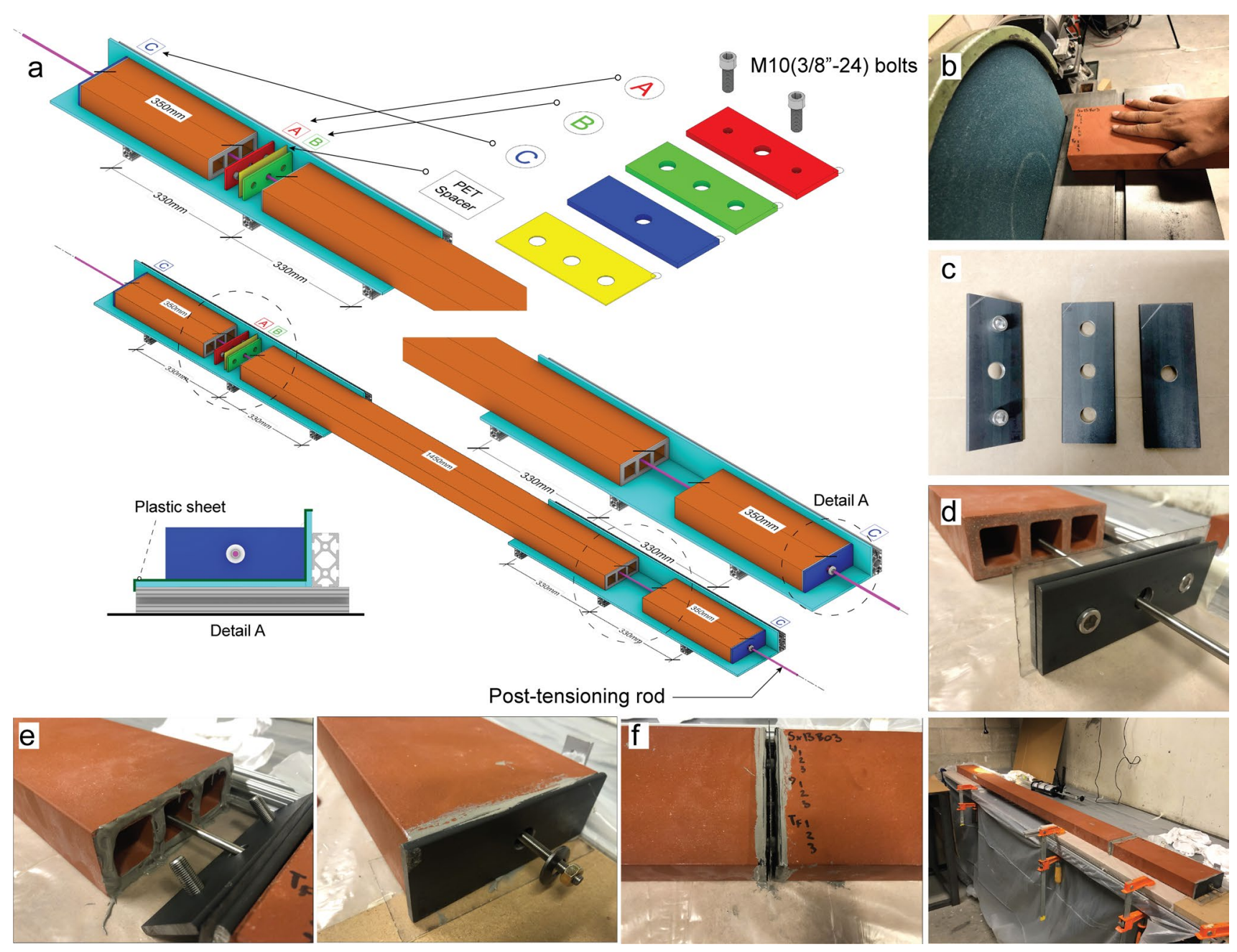

Fig. 8 Image showing construction-scale beam test assembly

Beam C The beam consisted of three segments, two connected with metal plates designed with shear dowels. The metal plates were bonded to the ceramic using high-strength epoxy, rated at $69 \mathrm{MPa}$ compressive strength. The other two segments were bonded without metal by gluing them together with the same epoxy. Post-tensioning system and forces were the same as for A.

\section{Beam assembly}

The assembly of Beam $C$ is discussed in detail below. Beams $\mathrm{A}, \mathrm{B}, \mathrm{B} 1$ and $\mathrm{B} 2$ were assembled following a similar process.

A two-part jig was designed using a 1010 T-Slot aluminum system to guide the gluing of the metal end plates to the ceramic beams (Beam A, Beam B and Beam B1 and B2) as well as the 3 segments of the beams (Beam C) to each other and, position the post-tensioning rod in the construction scale beam(Fig. 8-a). Two MDF sheets were placed on the 1010 aluminum structure to form a flat ' $\mathrm{L}$ ' shaped surface to act as an assembly guide. This surface was covered with a thin plastic sheet (shown in green) to prevent the beam from sticking to the jig while gluing. Once the jig was setup the beam assembly steps are as follows.

- The edge profiles of the beam were sanded with a mechanical sander to produce highly planar butt joints (Fig. 8-b).

- The 3 types of metal plates were fabricated out of $5.4 \mathrm{~mm}$ thick, $50 \mathrm{~mm}$ wide 5160 alloy steel plates with a yield strength of $668.8 \mathrm{MPa}$. Plate A and Plate B pair the beam at mid-span while two Plate C's serve as the end plates. For details see (Fig. 8-c). Two M10 bolts are threaded through Plate A.

- The three segments of the beam as well as the plates arranged on the jig, and the post tensioning rod (TriPyramid A22-0250) with $6.4 \mathrm{~mm}$ diameter is passed coaxially through the beam assembly. Two slip washers and a Grade 8 nut were added loosely to each end of the rod. 
Fig. 9 Image showing construction-scale beam testing setup

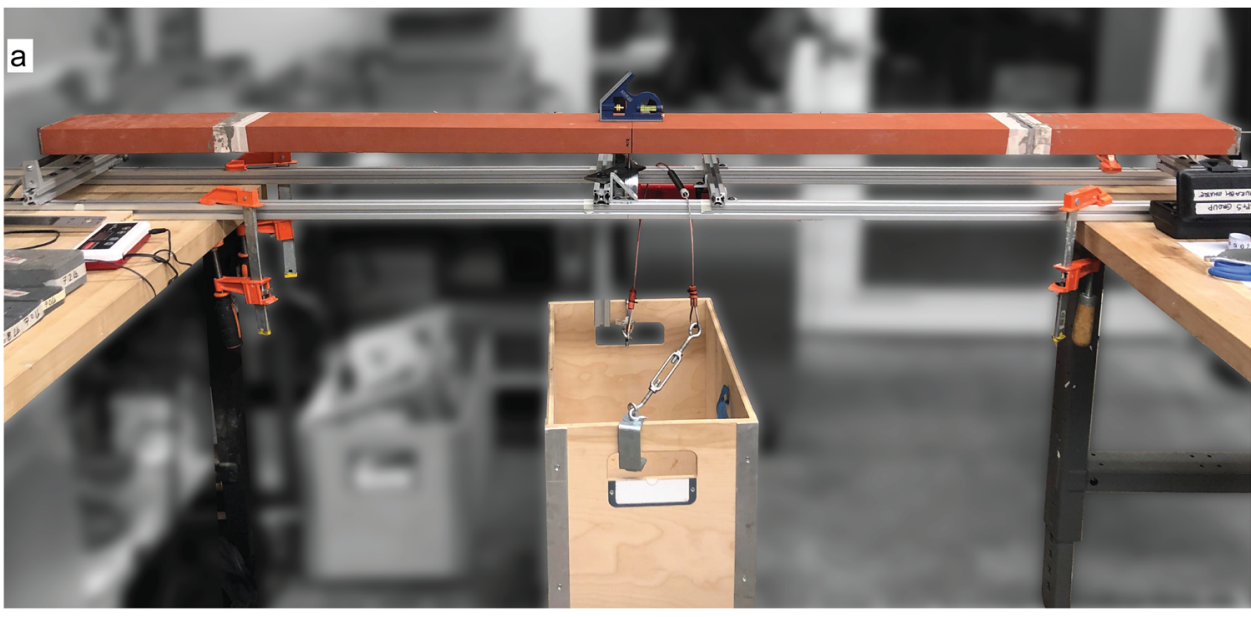

b

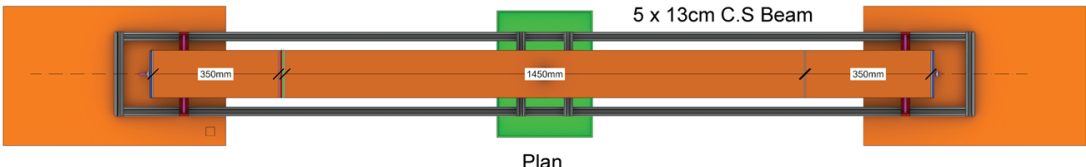

Plan

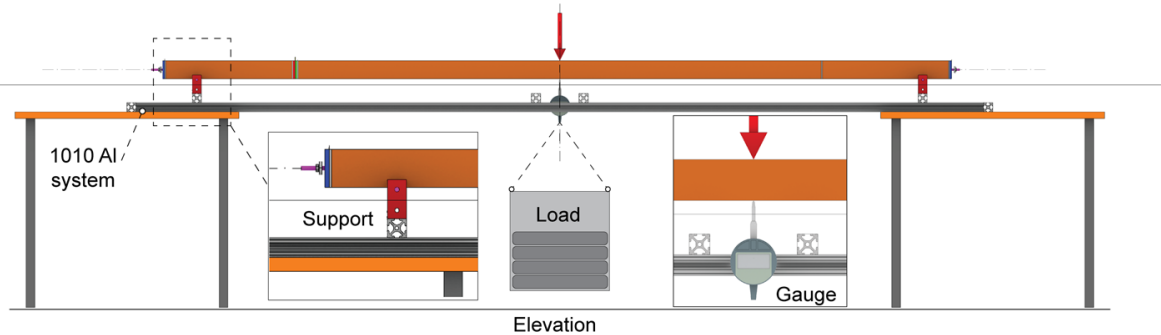

- As the structure was designed for disassembly, PET plastic separators similar to Plates B were cut and added to the assembly to avoid accidental adhesion of the plates during gluing (Fig. 8d).

- With all the parts loosely in place an epoxy adhesive (Simpson ET-HP Anchoring Adhesive) was used to connect the beam segments to the metal plates in one part of the beam (Plate A and B), the beam segments together to each other and the end plates (Plate C) to the end of the beam assembly. (Fig. 8-e)

- The post tensioning rod was slightly tightened to facilitate better adhesion while drying. Excess adhesive was wiped off, and the assembly was allowed to cure for $24 \mathrm{~h}$ at room temperature. (Fig. 8-f)

- With the epoxy fully set, the PET spacers were removed from the beam assembly and the beams were post-tensioned using a torque wrench.

\section{Test setup}

A three-point bending setup was designed and set up level on two strong tables. All supports were round steel rods, the load was suspended in the middle and induced through a round steel rod. Deflections were measured using a plunger-style electronic variance instrument [Fowler 54-520-255-0 Indi-X Blue] with a tolerance of $0.01 \mathrm{~mm}$. Loads were accurate to $0.44 \mathrm{~N}$. The setup is shown in Fig. 9. L was either $2140 \mathrm{~mm}$ (Beams A and C) or $1365 \mathrm{~mm}$ (Beams B, B1 and B2).

\section{Test results}

All beams were tested with relatively low loads such that deformations would remain in the elastic range without failure. Beams A, B and C was tested with 10 different levels of pre-stress, starting with a torque of $3.39 \mathrm{~N}$-m ending with a torque of $13.56 \mathrm{~N}-\mathrm{m}$. Loads are listed as point loads in $[\mathrm{N}]$. The torque - force conversion was the average value of 2-3 tests by TriPyramid Inc., the company that provided the post-tensioning rods. In addition to the external point load the self-weight of $0.832 \mathrm{~N} / \mathrm{mm}$ was factored in. ${ }^{3}$

${ }_{3}^{3}$ Bending stresses were calculated as follows: $\mathrm{M}=\left[\left(\mathrm{w} \mathrm{L} \mathrm{L}^{2}\right) / 8\right]+[(\mathrm{P}$ L) / 4] with $\mathrm{w}=0.832 \mathrm{~N} / \mathrm{mm} ; \mathrm{L}=2140 \mathrm{~mm}$ for beams $\mathrm{A}$ and $\mathrm{C}$, $\mathrm{L}=1365 \mathrm{~mm}$ for beam $\mathrm{B}$; the largest positive moment in the beams $\mathrm{A}$ and $\mathrm{C}$ at maximum point load was $0.166 \mathrm{kNm}$. Maximum tensile bending stresses can be found with: $f=[M / S]-[F / A]$ with $M$ the maximum moment, $\mathrm{F}$ the post-tensioning force, $\mathrm{S}$ the section modulus, and A the cross-sectional area of the profile. A positive number indicates the amount of residual tensile stresses, a negative number 
Fig. 10 Graphs showing load vs mid-span deflection for (a) Beam A, (b) Beam B, (c) Beam $\mathrm{B} 1$ and Beam B2 and (d) Beam C
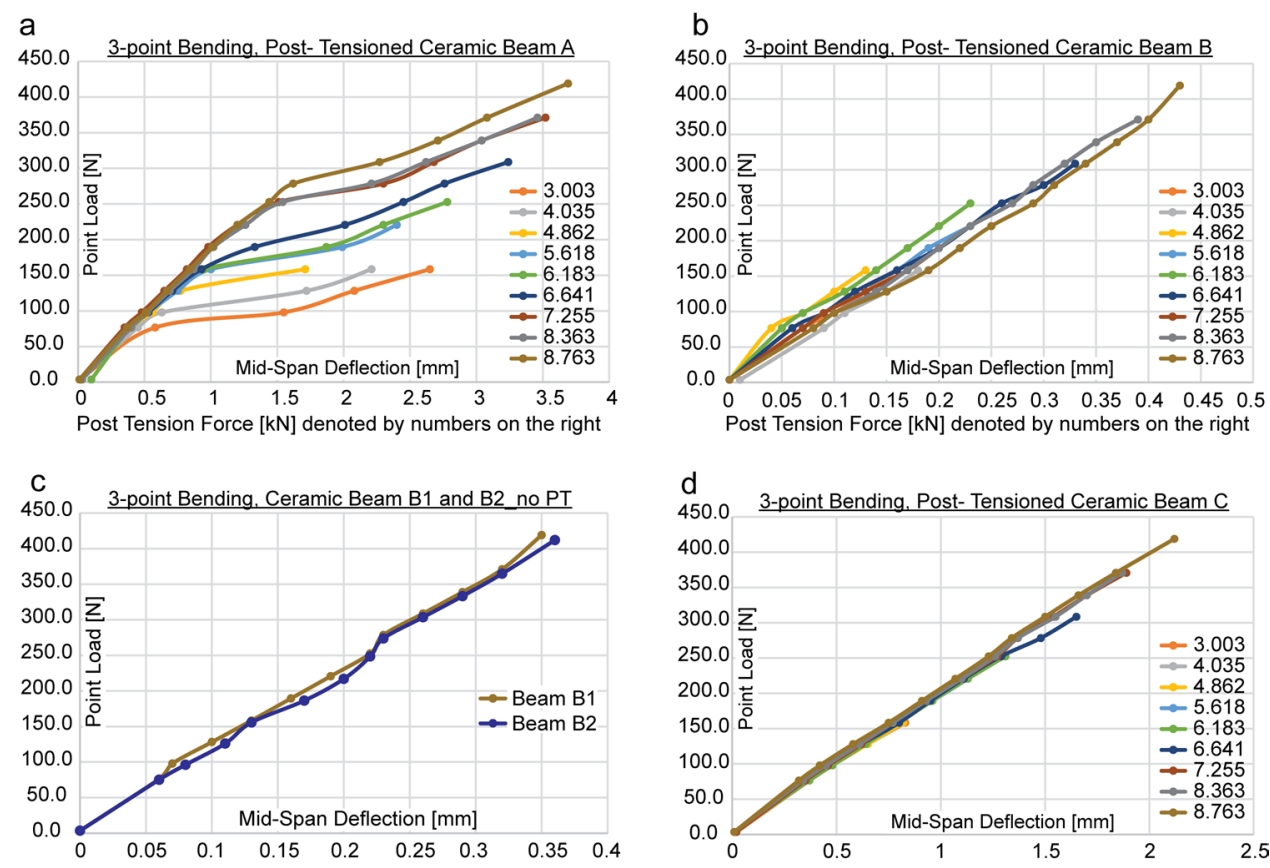

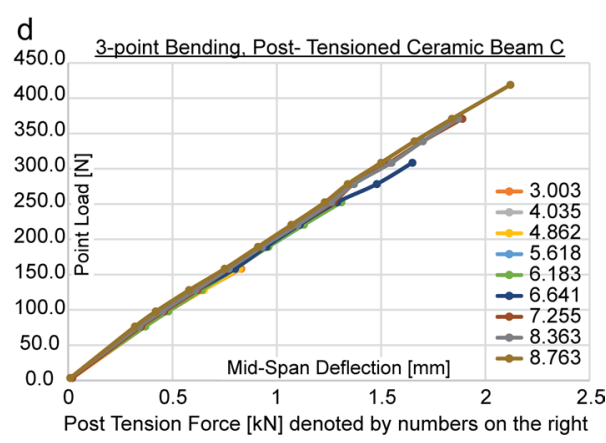

Beam a $(L=2140 \mathrm{~mm})$ The test results are shown in the Fig. 10-a. The graph shows a linear behavior up to a certain point of increased deflections. We observed that the metal connecting plates started to splay apart at higher loads, which would explain the larger deformations at higher loads. The behavior is linear in a fairly predictable way. The linear behavior persists longer for higher post-tensioning forces. The different series /colors are named after the post-tensioning force measured in $\mathrm{kN}$.

Beam B ( $L=1450 \mathrm{~mm})$ The graph in Fig. 10-b shows a linear behavior with a fairly consistent slope, but some deviation between tests. The different series /colors are named after the post-tensioning force measured in $\mathrm{kN}$. The shorter span, combined with the lack of connector plates, make for an overall stiffer beam. At a point load of $419 \mathrm{~N}$, the deflection is $0.43 \mathrm{~mm}(\mathrm{~L} / 3372)$ compared to $3.69 \mathrm{~mm}(\mathrm{~L} / 583)$ for beam A. Beams B1 and B2: Same span and load as Beam B, but no post-tensioning. The test was used primarily to calculate the modulus of elasticity of the ceramic material (Fig. 10-c).

Beam C ( $L=2140 \mathrm{~mm})$ The test results are shown in the Fig. 10-d. The graph shows a linear behavior with a very consistent slope, but some deviation between tests.

The different series /colors are named after the post-tensioning force measured in $\mathrm{kN}$. Beam $\mathrm{C}$ is stiffer than beam

\section{Footnote 3 (continued)}

indicates that the tensile zone is subject to compressive stress due to post-tensioning stress overriding the tensile bending stresses.
A with the same span. The difference between the beams is the absence of one metal to metal plate construction joint. At a point load of $419 \mathrm{~N}$, the deflection was $2.12 \mathrm{~mm}(\mathrm{~L} / 1009)$ compared to $3.69 \mathrm{~mm}(\mathrm{~L} / 583)$ for beam $\mathrm{A}$, indicating that proper joint design and execution is key to structural performance of post-tensioned ceramic extrusions. Maximum residual tensile bending stresses for Beams $\mathrm{A}$ and $\mathrm{C}$ were $2.687 \mathrm{MPa}$, or about $10 \%$ of the experimentally determined limit stress. Maximum bending stresses for Beams B1 and $\mathrm{B} 2$ are $3.6 \mathrm{MPa}$. These stresses are equal in the compression and in the tension zone.

\section{Modulus of elasticity}

Based on the test results of beams B1 and beam B2, and averaged over all loadings, the Modulus of Elasticity E was found to be $55,025 \mathrm{MPa}$, with a relatively small standard deviation for each test (B1: $3292 \mathrm{MPa}, \mathrm{B} 2: 2222.9 \mathrm{MPa}$ ). This value is much higher than the Modulus of Rupture found when testing the shorter beams, with or without posttensioning. E for the longer beams is an equivalent value as it incorporates the effect of the post-tensioning member.

\section{Design values}

Based on the test results the following assumptions were established for the purpose of guiding the structural design of the prototype systems discussed next. Allowable bending stresses were set at $17 \mathrm{MPa}$, representing a safety factor of 1.7 compared to the experimental average of $29 \mathrm{MPa}$. 
Fig. 11 a Perspective rendering and (b) plan drawing of the Vierendeel Arch. The segment of this larger structure that was fabricated as the Vierendeel Arch Prototype is identified with a dashed red line

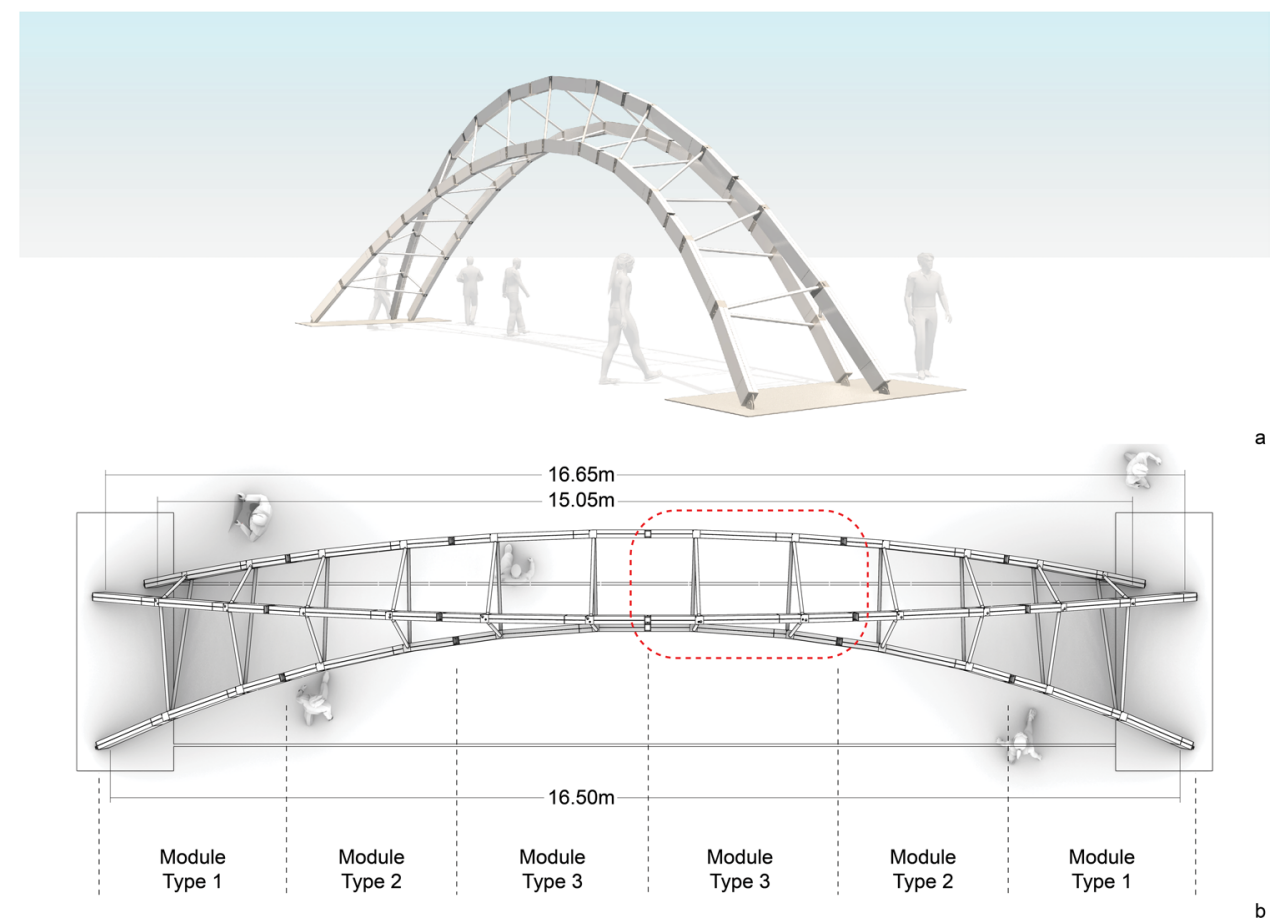

Young's Modulus was set at a conservative value of $12,000 \mathrm{MPa}$, a value similar to that determined in the tests of short beam segments (with or without post-tensioning), but significantly lower than the value determined in the longer beam tests.

\section{Results}

\section{Proof-of-concept prototypes}

The prototypical post-tensioned ceramic structures presented here were installed at the 2019 and 2020 editions of CEVISAMA in Valencia, Spain as a part of the Transhitos exhibition, coordinated by the Área de Hábitat del Instituto de Tecnología Cerámica (ITC). Fabricated in 2019, the Vierendeel Arch Prototype represented a module of a larger Vierendeel arch structure, composed of 3 primary arches connected with thin struts such that non-funicular loadings result in bending moments. The Hypar Tower, constructed in 2020, consists of 24 ceramic struts arranged to define two pairs of stacked hyperbolic paraboloids, or hypars, measuring $6 \mathrm{~m}$ in height.

\section{Vierendeel arch prototype}

With a span of $15.1 \mathrm{~m}$, the design of the Vierendeel Arch is comprised of three main arch elements connected with thin struts in a Vierendeel pattern such that buckling and deflection are controlled (Fig. 11). The design of the three main arches consists of hollow extrusions with an exterior dimension of $250 \mathrm{~mm} \times 60 \mathrm{~mm}$, doubled up into a section $250 \mathrm{~mm} \times 120 \mathrm{~mm}$. A $10 \mathrm{~mm}$ gap between both sections accommodated for dimensional variation along the length of the extrusions - its positive effect on the moment of inertia was ignored in the structural analysis. The connecting struts consist of hollow pipe extrusions with a $50 \mathrm{~mm}$ outer diameter. Struts and arches are post-tensioned with steel members placed inside the extrusions such that bending stresses are controlled and moment resistance is improved. The primary arch elements are post-tensioned with cables, while the connecting struts utilize threaded steel rods. The connecting nodes feature an exterior shell consisting of metal plates and 3D printed (3Dp) elements uniquely shaped to accommodate the angles of each connecting strut. Each 3Dp node shell is filled with concrete to provide stiffness. This approach allows for a high degree of geometric flexibility and minimizes the number of complex on-site connections. To facilitate rapid assembly on site, the arch was designed to be prefabricated off site as six construction modules and attached together with a bolted connection once on site. The presented research included design detailing, structural analysis, and construction sequencing for the entire structure. To confirm the feasibility of the proposed construction detailing and sequencing, one of the six proposed construction modules, referred to here as the Vierendeel Arch Prototype and measuring $3.32 \mathrm{~m} \times 1.78 \mathrm{~m} \times 1.95 \mathrm{~m}$ was fabricated at full scale. 


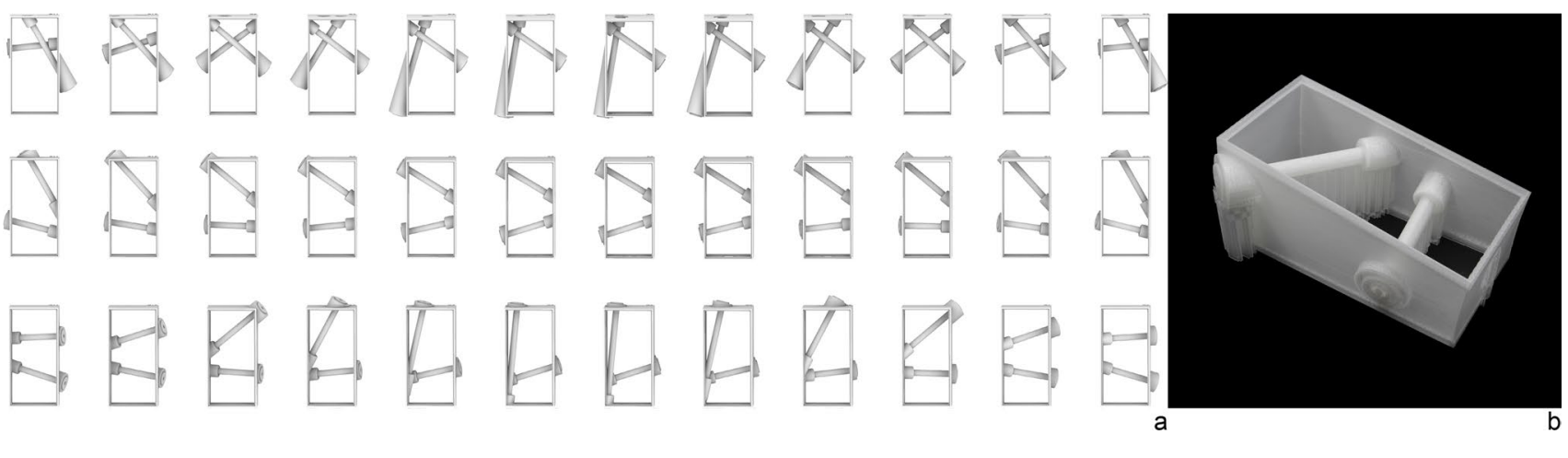

Fig. 12 Cross-section views of the 36 unique 3D printed node shells of the Vierendeel Arch showing the geometric adaptability of the system (10a) and photograph of a typical 3D printed node shell (10b)

\section{Form-finding and analysis}

The geometry of the Vierendeel Arch was defined by three catenary curves controlled by a total of 13 independent geometric parameters. The geometry of each curve was defined by three parameters: horizontal span, the length of the catenary chain in relation to the span, and the orientation of the curve in relation to vertical. Each of the two outer arches included two additional parameters which specified the lateral distance of each springing point from the springing of the central arch. Parameter domains were determined by constraints of the project site and available material sizes. Two additional parameters determined the Vierendeel connection pattern - a maximum allowable arch segment length $(1.6 \mathrm{~m})$ and connecting strut length $(2.5 \mathrm{~m})$. Each of the catenary curves was subdivided into an equal number of segments based on the ratio of the longest catenary curve length to the maximum allowable arch segment length. Connecting struts were placed at the location of these division points. The maximum allowable connecting strut length determined the placement of struts between adjacent arches - division points between adjacent arches greater than this threshold value were not connected by an intermediate strut.

A comprehensive parametric model was created using the parameters described above using Rhinoceros 6.0 and Grasshopper. The model enabled the research team to rapidly iterate through design options during early phases of the design process; understand the structural implications of changes to design geometry via finite element analysis (FEA); discretize the form into construction elements; detect clashes between post-tensioning hardware; and generate cutting schedules for ceramic extrusions and print geometry for the 3Dp structural nodes.

The wireframe model created by the subdivided catenaries and connecting struts was input into the FEA plugin Millipede, which incorporated material-specific properties (modulus of elasticity, Poisson's ratio, material density) and structural characteristics of the selected cross sections for each wireframe element (cross sectional area, moments of inertia [Iyy + Izz] and torsional constant $[\mathrm{Jxx}])$. The FEA model did not account for the weight of post-tensioning hardware or other construction joints.

The 13 independent design geometry parameters, and the maximum deflection of the structure as calculated by the FEA were input into Galapagos, a genetic algorithm-based generic solver included in the Grasshopper software [27]. The geometry parameters established the genome while the maximum deflection value for each design iteration was used as the fitness value. While the solution with the smallest deflection as determined by the solver was not ultimately selected for the final arch geometry, the evolutionary solver allowed the design team to quickly understand the design space of the project, evaluate modifications to the geometry of the three main arches, and identify a point of intersection between the desire for an efficient structural solution that was visually compelling and demonstrative of the expressive potential of the structural system.

The research team tested multiple extrusion configurations for the ceramic arch members - including paired $130 \times 50 \mathrm{~mm}$ extrusions and vertically stacked configuration of $250 \times 60 \mathrm{~mm}$ extrusions. Ultimately $250 \times 60 \mathrm{~mm}$ was selected for reasons of structural performance and aesthetics. A subsequent set of parameters tested the impact of rotating the extrusions which comprised the arch about the structural centerline. Once a design geometry was selected a second portion of the parametric model automated several design detailing processes, including the generation of a cutting schedule for ceramic extrusions and the design detailing of 3Dp connecting nodes.

\section{D printed node}

The nodes at which the struts and arches connect use a combination of standardized metal plate connections and a 3Dp shell that is unique to each node (Fig. 12). This approach allows for a high degree of geometric flexibility, minimizes 


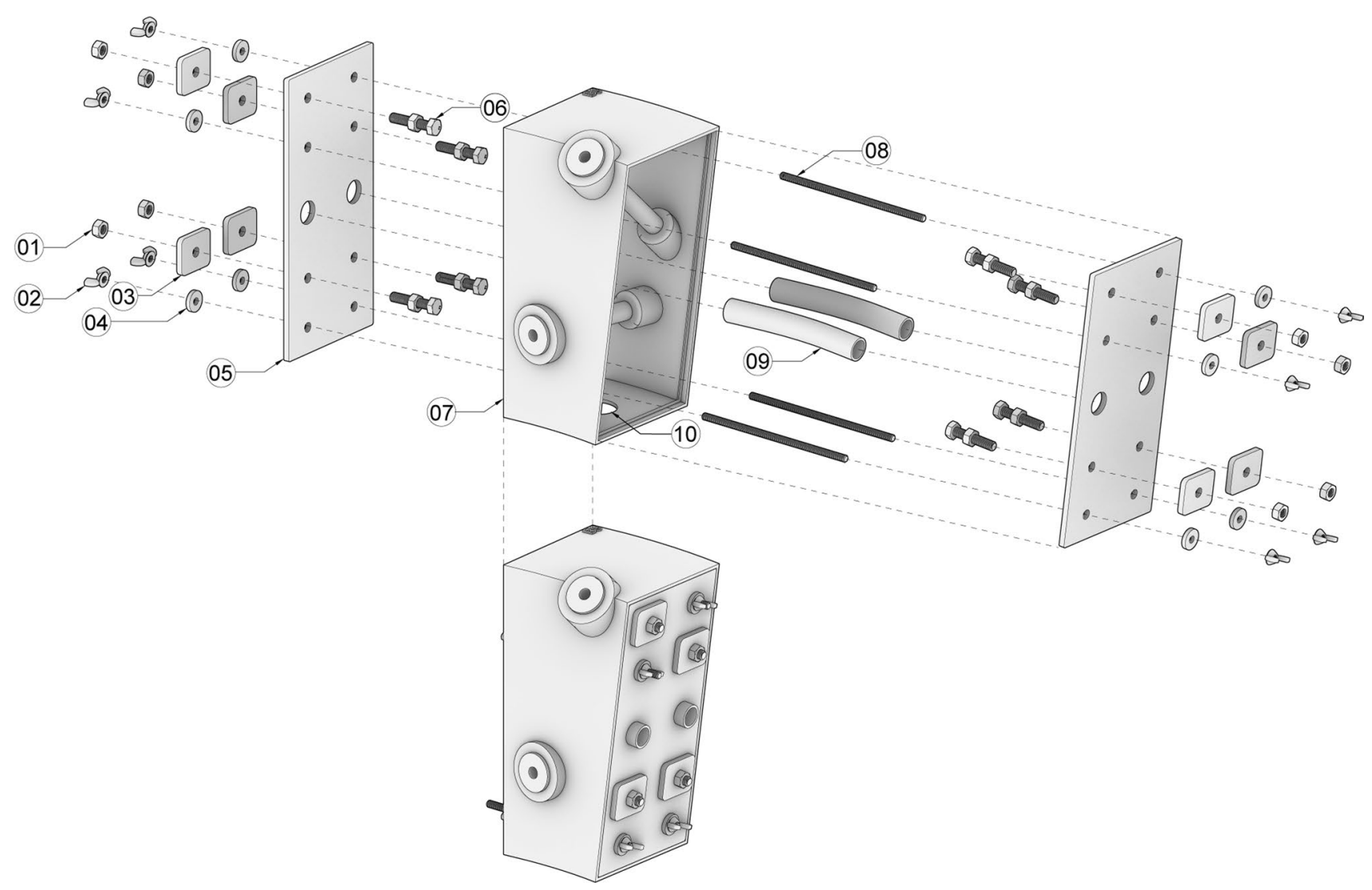

Fig. 13 Exploded axonometric drawing showing components of the connecting node assembly: 01. Hex Nut; 02. Wing Nut; 03. $5 \mathrm{~mm}$ Thick Metal Alignment Plate; 04. Rubber Washer; 05. 5 mm Thick

the number of complex connections on site, simplifies fabrication as each ceramic extrusion is cut at a 90-degree angle, and provides a way for the design team to embed element labels directly into the node geometry. The geometry of the nodes was controlled by a series of parameters in the digital model which could be adjusted independently per arch to avoid collisions between internal post-tensioning members. Dimensional parameters included in-plane offset of struts $(45-50 \mathrm{~mm})$, the lateral offset of the strut toward the outside of the structure $(0-20 \mathrm{~mm})$, the minimum width (along the length of the primary arches) of the 3Dp node $(40-60 \mathrm{~mm})$, and the location of an access hole for the pouring of concrete into the joint after assembly. Additional accommodations for the dimensions of post-tensioning hardware included the depth of integrated alignment discs to register the intermediate strut on the print, the internal radius of an integrated sheath for strut post-tensioning tendons, the inset depth and radius for the associated strut hardware.

The $50 \mathrm{~mm}$ diameter strut tubes rest on a $3 \mathrm{~mm}$ thick plastic surface that is $3 \mathrm{D}$ printed. According to the manufacturer the tensile strength of the filament is $47 \mathrm{MPa}$ and the bending strength is $73 \mathrm{MPa}$. No compressive strength is
Metal Bearing Plate; 06. Bolt; 07. 3D Printed Node Formwork; 08. Threaded Rod; 09. Post-Tensioning Tendon Conduit

provided, but compressive strength is assumed to be equal to the bending strength. Stresses in the struts are generally lower than $3.5 \mathrm{MPa}$, so well below an acceptable level. The metal plates and 3Dp piece are assembled into a formwork that is then filled with concrete (Fig. 13).

\section{Structural module design}

The approach taken during structural design was to analyze the system with all gravity loads and determine the members with the largest tensile bending stresses - usually a combination of axial and bending stress (Fig. 14). The posttensioning force was then sized such that it produces compressive stress at the same magnitude as the tensile bending stresses.

The Vierendeel Arch was designed to be prefabricated off-site and transported to the exhibition in sections. The arch was thus divided into three module types, symmetrical on each side for a total of six. Modules are connected to each other with a bolted construction joint at each of the three primary arches (Fig. 15). The arch as a whole is therefore not post-tensioned, only individual modules are post-tensioned. 


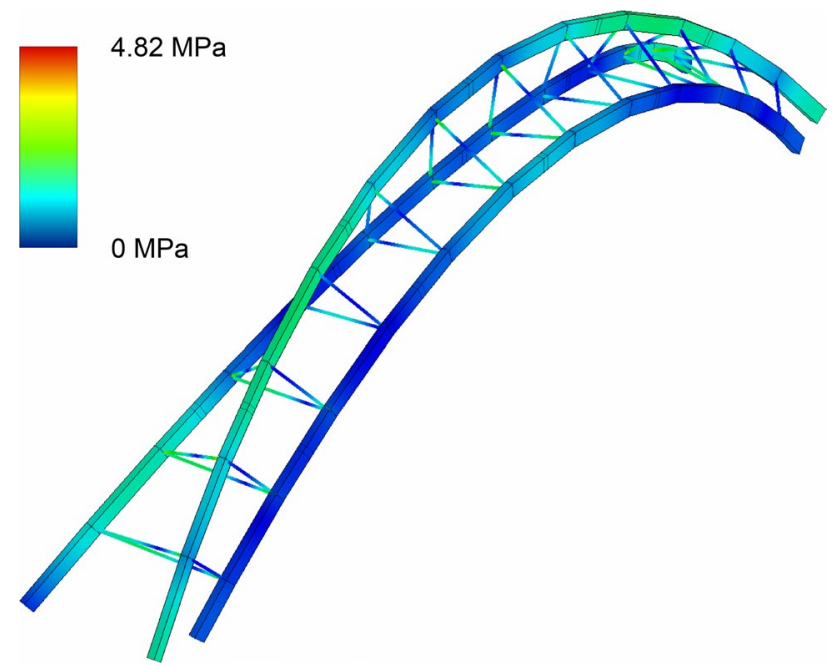

Fig. 14 Diagram showing maximum combined bending stresses and axial stresses of the Vierendeel Arch. Maximum combined bending stresses and axial stresses were $4.82 \mathrm{MPa}$, thus well below the allowable limit. These stresses occur in the second and third set of struts counting from the support forces present and serve as end plate anchoring mechanisms for the arch post-tension system. Based on this principle the required post-tensioning forces are listed in Table 3. Only module Type 1 features different post-tensioning forces in the two strut systems, to keep forces low and prevent buckling, with the lower value applied to the struts closer to the arch supports. The resultant combined maximum compressive stresses are well below the allowable limits.

\section{Post-tensioning system}

The tension elements of the Vierendeel Arch were comprised of $13 \mathrm{~mm}$ diameter braided steel cables with end fittings for the arches, and $6 \mathrm{~mm}$ diameter threaded rods for the cylindrical struts. The elements were sized based on prescribed post-tensioning forces. The end fittings featured threaded connectors such that the required forces can be applied with a torque wrench. The arch tension elements are connected to the construction joints which in turn transfer all forces and moments between adjacent modules. Some of the

Fig. 15 Detail of construction joint at the connection between arch modules showing (a) top view and (b) isometric view. 01 . Welded metal endcap; 02. Hole for post-tensioning tendon; 3 . Hole for on-site bolted connection; 4. Post-tensioning tendon; 5. Primary arch member; 6 . Bolt

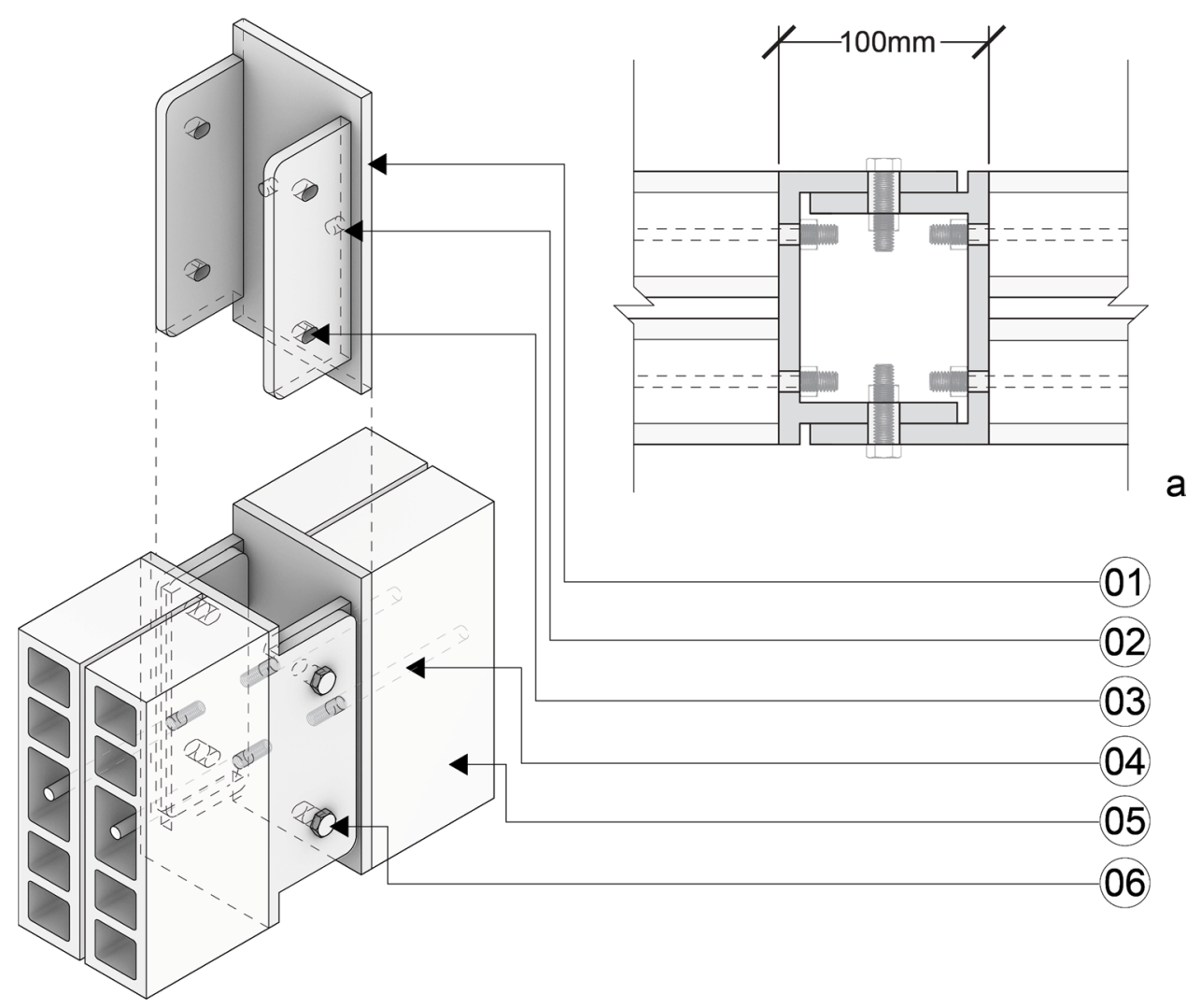

Within each module the struts and the arches each have their own level of post-tensioning force that remains constant within the module. The joints transfer the moments and axial arches and struts are split in two elements along their length, connected with a metal shear plate. The post-tensioning tie 
Table 3 Vierendeel Arch module types and post-tensioning forces, installed condition

\begin{tabular}{llll}
\hline $\begin{array}{l}\text { Post-Tension- } \\
\text { ing Force }(\mathrm{kN})\end{array}$ & Module Type 1 & Module Type 2 & Module Type 3 \\
\hline Arches & 17.5 & 17.25 & 10 \\
Struts & 4.3 and 5.5 & 6.1 & 4.0 \\
\hline
\end{tabular}

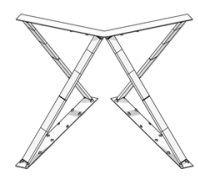

01

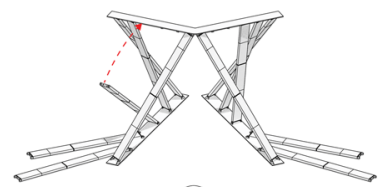

02

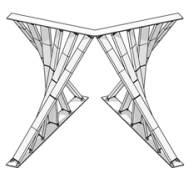

03

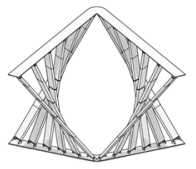

04

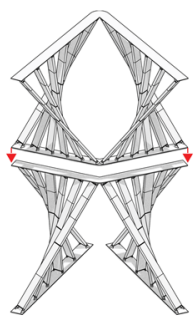

05

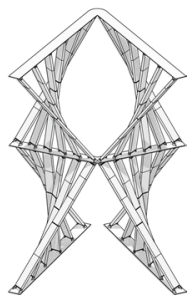

06

Fig. 16 Diagram showing the assembly sequence of the Hypar Tower. 1) Installation of outmost struts 2) upward rotation of intermediate struts 3) completed lower tower section and 4) completed upper section 5) placement of upper section on lower section 6) completed structure

is continuous and ensures that all bending moments or axial tensile forces can transfer nevertheless.

\section{Hypar tower}

The $6 \mathrm{~m}$ tall Hypar Tower utilizes industrially produced hollow ceramic extrusions measuring $250 \mathrm{~mm} \times 60 \mathrm{~mm}$ in cross-section, identical to those used in the main arch segments of the Vierendeel Arch. The extrusions are assembled into 24 post-tensioned struts such that a vertical, two-level structure can be constructed. The system consists of the struts, horizontal steel stiffener plates, and a base that provides support and allows for the system to be leveled on site. Ranging in overall length from 2.905 to $3.583 \mathrm{~m}$, the inclined struts are subject to bending by design.

\section{Assembly sequence}

The Hypar Tower featured a novel assembly sequence designed to accommodate for both the compressed installation schedule the prototype exhibition and the material constraints of the ceramic elements - primarily the risk of brittle fracture of the struts during transport and assembly. Each strut was post-tensioned on flat ground prior to placement in the structure. The placement and orientation of each strut within the structure was controlled by $8 \mathrm{~mm}$ thick metal support flanges welded to each support plate. The connections between the support plate and the strut interface were designed to be bolted in place during the initial offsite assembly of the prototype, to then be welded in place thus forming a moment connection once installed in a stable structure that allowed for the removal of the temporary scaffold. Intermediate struts were then loosely fastened to the support flanges at their lower connection points and rotated upwards to connect to the upper support plate (Fig. 16). The bolted connection at each support flange was then augmented with a continuous fillet weld to create a moment connection at the strut/support plate interface. Finally, the upper half was lifted into place and mechanically fastened to the lower half to complete the structure (Fig. 17).

\section{Connection detailing}

Each ceramic strut was comprised of 4 or 5 ceramic extrusions ranging in length from $0.579 \mathrm{~m}$ to $0.9 \mathrm{~m}$. A construction joint was located roughly at mid-span of each strut. This facilitated some degree of prefabrication while minimizing the potential for brittle fracture during transit. Metal end caps were designed to distribute the load evenly over the end sections of the extrusion profiles, ensuring that no significant tensile bending stress developed. The mitigation of uneven ceramic end surfaces was handled through a structural epoxy grout that bonded steel to the ceramic, and adjacent ceramic extrusions to one another, while avoiding stress concentrations. The plates used a system of M8 bolts and laser cut holes to register adjacent end caps with one another and control shear stresses. The detail of the strut connections allowed for struts to be fully post-tensioned prior to the final installation (Fig. 18). 
Fig. 17 Images showing (a) upper tower section in transit via crane and (b) placement of upper tower section on lower tower section
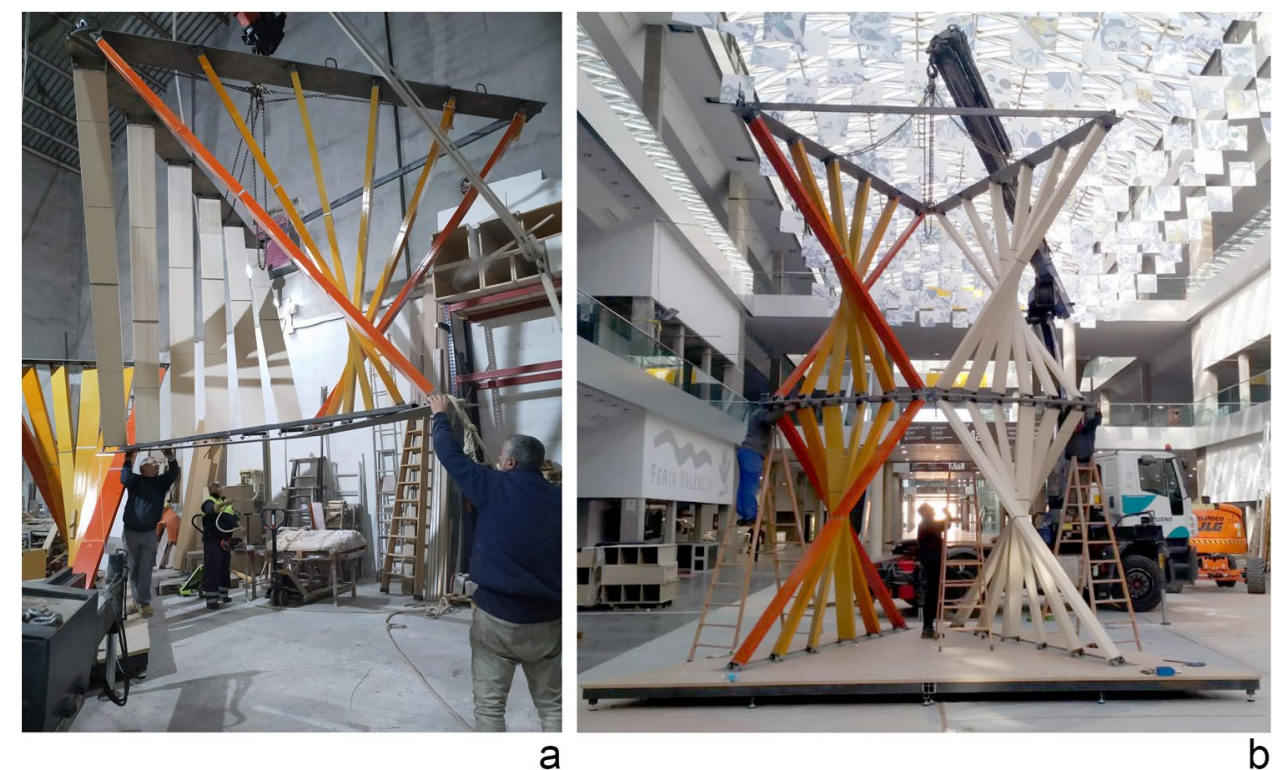

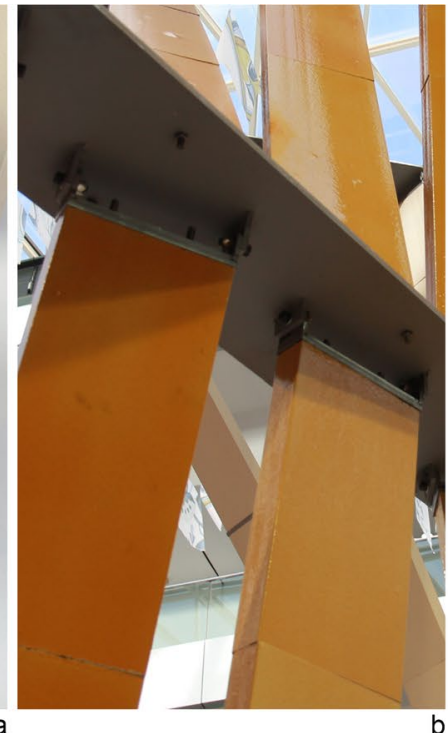

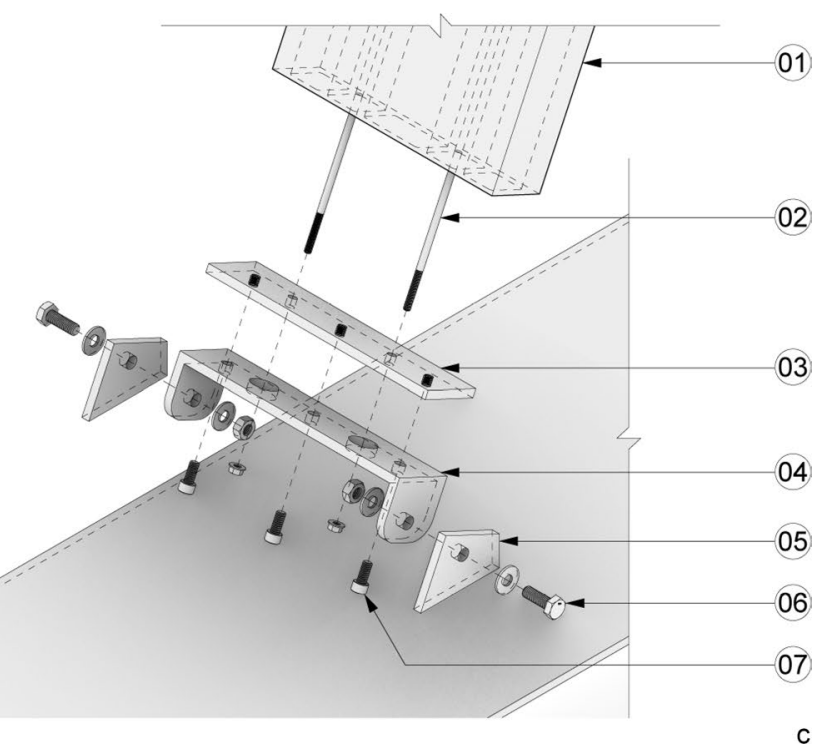

Fig. 18 Detail images of the strut/support plate connection interface at (a) lower and (b) middle support plates. (c) Exploded axonometric drawing showing components of the strut connection: 01. Ceramic

\section{Post-tensioning system}

The post-tensioning system employed $16 \mathrm{~mm}$ diameter B500 steel reinforcing bars commonly used in reinforced concrete construction, threaded with M12 threads at each end and post-tensioned with a force of $6 \mathrm{kN}$. The use of modified reinforcing bars as post-tensioning elements was driven by pragmatic concerns of procurement speed, available element lengths, and material cost.
Extrusion; 02. Post-tensioning Tendon; 03. Metal Endcap; 04. Connection Bracket; 05. Support Flange; 06. M10 Bolted Connection; 07. M8 Socket Head Bolt

\section{Structural analysis}

Three versions of the system were modelled in Multiframe version 21.14.00.04, using custom-built sections, and differing solely in the type of steel profiles used for the horizontal stiffener plates. All versions had the same ceramic sections. Ultimately a stiffener steel plate with the cross-section of $300 \times 10 \mathrm{~mm}$ was selected for its slender appearance and ease of fabrication and construction. The middle plate was 
Table 4 Maximum bending stress and compensating post-tensioning force

\begin{tabular}{|c|c|c|c|c|c|c|}
\hline Member No. & $\mathrm{f}_{\mathrm{b}} \max (\mathrm{MPa})$ & Area $\left(\mathrm{mm}^{2}\right)$ & $\begin{array}{l}\text { Min. Post Tension Force } \\
\text { Needed }(\mathrm{kN})\end{array}$ & Axial Compression $(\mathrm{kN})$ & Total Axial $(\mathrm{kN})$ & Additional Safety Factor \\
\hline $127 / 139$ & 1.369 & 7064 & 9.67 & 0.531 & 10.2 & 2.92 \\
\hline
\end{tabular}

divided into two $5 \mathrm{~mm}$ thick plates in order to allow for the lower and the upper segments to be assembled separately. Bolting the plates together frequently created a section similar in stiffness to the single $10 \mathrm{~mm}$ plate used in the structural model. The connections between both struts and the middle plate was modeled as a rigid connection achieved by a pair of post-tensioned steel bolts. The overall goals of the structural design were to control deflections, ensure that bending stresses in the ceramic struts are well below the allowable limit, and ensure that the struts did not buckle due to the post-tensioning force.

\section{Stresses in bending}

The largest bending stresses in the struts were roughly at midspan, and in the weak direction of the cross-section. The largest bending stresses at the connection to the middle plate occur in the elements that are most steeply inclined. All bending stresses are well below the maximum permissible bending stress of $17 \mathrm{MPa}$.

\section{Post-tensioning}

The required post-tensioning force was determined such that all bending stresses at the end connector plates were eliminated, leaving thus some residual bending stresses at midspan. These residual stresses are in the order of $1 \mathrm{MPa}$ or lower, thus far below the allowable limit. Bending stresses $\mathrm{f}_{\mathrm{b}}$ at the end connections and the compensating post-tensioning forces are listed in Table 4 below.

\section{Deflections}

Maximum nodal displacements were very small at 2-3 $\mathrm{mm}$. Bending deflections for the struts are at most $12 \mathrm{~mm}(\mathrm{~L} / 300)$ roughly at midspan for the most steeply inclined outermost struts (Fig. 19). Given the strut length of approximately $3.6 \mathrm{~m}$ this deflection was considered acceptable since it was similar to what had been measured in tests of the longer beam specimen that had shown no sign of fracture.

\section{Member buckling}

Struts were checked for buckling by determining the critical buckling load around the weak axis. Assuming a Young's Modulus of $12,000 \mathrm{MPa}$ the critical buckling load of the longest strut was $30 \mathrm{kN}$, well below the actual maximum axial force present anywhere in the system. There is some uncertainty as to what should be reasonably assumed as Young's modulus. The total axial loads listed in the table above are far below this number, as indicated by the safety factor for buckling.

\section{Conclusions}

There are no compelling technical reasons why ceramic extrusions could not be deployed in a primary structural function. Tests on smaller specimen established a first baseline knowledge for maximum strength values as well as Young's modulus, these values were then confirmed or revised through tests of beams at a realistic scale of structural components. Fired extrusions - like all ceramics - are brittle and sensitive to local cracking because of stress concentrations. In the case of post-tensioned elements, care must be taken to avoid localized stresses where the posttensioning force is being induced into the elements. At the interfaces between metal end caps and the extrusions it is recommended to apply a thin, epoxy-based layer to eliminate
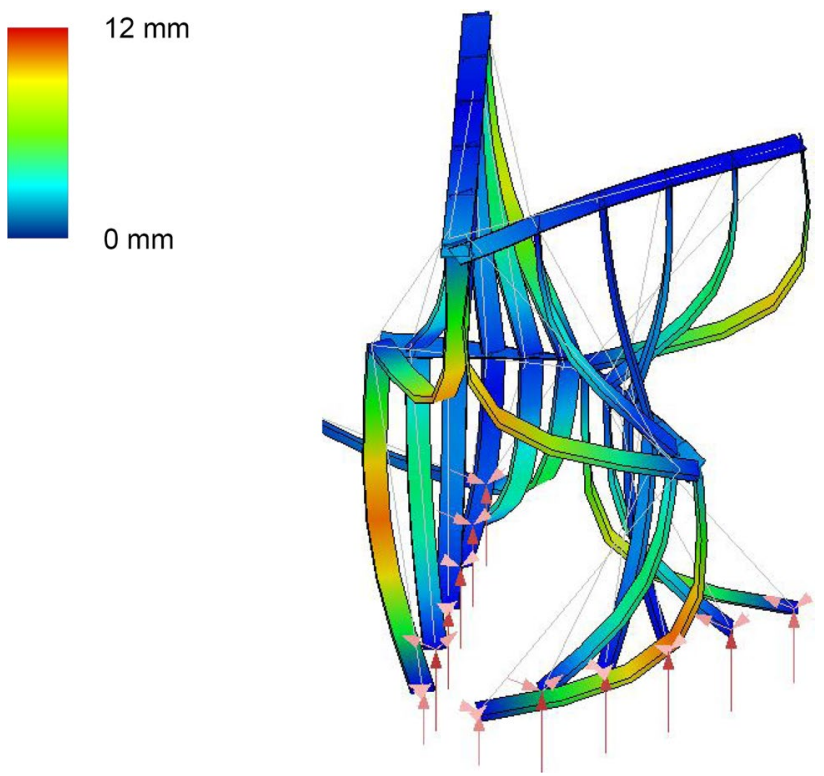

Fig. 19 Diagram showing bending deflections of the Hypar Tower under self-weight 
stress concentrations and significantly reduce the variations in load bearing capacity.

Precision length cutoffs will assist this effort. These are relatively easy to accomplish with the use of industry-standard CNC saws. It is entirely possible that precision grinding of the end faces of extrusions could allow for the elimination of the epoxy interlayer. Grinding is routinely performed in the production of precision tiles or ceramic washbasins, so does not present an obstacle in the industry.

Ceramic extrusions have good potential for post-tensioning due to their high compressive strength and demonstrated longevity. More research and full-size prototypes are needed to determine acceptable safety factors within the context of various applications in buildings and beyond. Temperature effects and the different responses of the tendons and the ceramics to temperature fluctuations need to be investigated. The same is true for changes in relative humidity, which might have dimensional effects on the ceramic especially if the clay has not been fired to a level of full vitrification.

Looking beyond these solvable technical uncertainties it can be concluded that the relative ease of developing and economically producing limited production runs of custom extrusion opens a large space of opportunity for structural applications. The present study utilized industry standard profiles that have been created for applications on building facades, and these same profiles could easily be improved and more substantially redesigned for a use in primary or secondary structural applications. Considering this we outline possible application scenarios in the following section - all of which would require additional research and demonstration in full-size pilot projects and prototypes.

\section{Future work}

\section{Applications}

What might the future hold for post-tensioned ceramic extrusions?

\section{Floor slabs}

Loads in slabs tend to be low - with residential loads in the order of $1.5 \mathrm{kN} / \mathrm{m}^{2}$ and office loads about $2.4 \mathrm{kN} / \mathrm{m}^{2}$. With common spans in the order of 6-9 $\mathrm{m}$ the use of ceramic posttensioned systems is technically feasible. Metal tendons can be designed to be fully enclosed by ceramic, and additional treatments can ensure sufficient fire resistance of the overall system. Advantages of this system would be the need for only minimal scaffolding that could be eliminated if posttension elements are pre-assembled on or off site and lifted into place. Extrusions could be shaped in hollow T or TT sections such as to provide both structural depth as well as the desired flat upper surface. In-plane shear strength could be provided by filling in the longitudinal element seams with a cementitious grout where needed.

\section{Pedestrian beam bridges}

Traditional steel, concrete or timber bridges have long been plagued by high life-cycle maintenance costs, independent of their spans. With beams as load collectors, ceramic bridges seem possible for shorter spans where the durability and low maintenance cost of ceramics would be a compelling argument compared to competing systems. Modular construction can be rapid and cost-effective if looked at over the life of the structure. In order to ensure a long service life of ceramic bridges it is important to prevent corrosion of the post-tensioning elements. A possible solution is to use stainless steel or epoxy-coated post-tensioning elements, both of which have been demonstrated to provide excellent resistance against corrosion in bridge construction [28, 29].

\section{Exterior yard and facade structures}

Ceramic pergolas, sun-shading elements and similar secondary structural elements are certainly conceivable to be built from ceramics, and future spans could significantly expand beyond what is common today.

The flexible color choices and durability of ceramic system might be of particular interest here.

Acknowledgements The authors thank ASCER Tile of Spain for their continuing support. Cevisama 2019 and 2020 provided additional support for the exhibition of the design prototypes. Javier Mira from the Instituto de Tecnología Cerámica as well as Groupo on Market helped realize the design. Windmill Structural Consultants S.L.P. provided the structural peer review. Simpson Gumpertz \& Heger assisted with compression testing. TriPyramid Structures Inc. designed and fabricated hardware for the construction-scale prototype beams. We would also like to thank Natalia Bechthold and Olga Mesa for their contributions during the prototype design process.

\section{Declarations}

Conflict of interest On behalf of all authors, the corresponding author states that there is no conflict of interest.

\section{References}

1. Shushkewich KW (2012) Eugène Freyssinet—invention of Prestressed concrete and precast segmental construction. Struct Eng Int 22(3):415-420. https://doi.org/10.2749/101686612X13363 869853338

2. Bechthold M (2015) Ceramic material systems: in architecture and interior design. Birkhäuser, Basel

3. Lourenço PB, Vasconcelos G (2015) The design and mechanical performance of high-performance perforated fired masonry bricks. In: Pacheco-Torgal F, Lourenço PB, Labrincha JA, Kumar 
S, Chindaprasirt P (eds) Eco-efficient masonry bricks and blocks, vol 2. Woodhead Publishing, Oxford, pp 13-44. https://doi.org/ 10.1016/B978-1-78242-305-8.00002-4

4. Brand S (1994) How buildings learn: what happens after they're built. Viking, New York

5. Bechthold M (2016) Ceramic prototypes - design, computation, and digital fabrication. Informes de la Construccion 68(544):e167-e167. https://doi.org/10.3989/ic.15.170.m15

6. King N, Bechthold M, Kane A, Michalatos P (2014) Robotic tile placement: tools, techniques and feasibility. https://doi.org/10. 1016/J.AUTCON.2013.08.014

7. Weston, M. (2013). Prime Negatives: Parametric Sponge-Forming and Slip Casting for Ceramics. In Proceedings of the XVII Conference of the Iberoamerican Society of Digital Graphics - SIGraDi: Knowledge-based Design (pp. 396-399). Presented at the XVII Conference of the Iberoamerican Society of Digital Graphics SIGraDi: Knowledge-based Design, Valparaiso, Chile: Editora Edgard Blücher. https://doi.org/10.5151/despro-sigradi2013-0075

8. Kwon H (2002). Experimentation and analysis of contour crafting (CC) process using uncured ceramic materials (Unpublished $\mathrm{PhD}$ Dissertation). University of Southern California

9. Seibold Z, Hinz K, Garcia del Castillo López, J. L., Martinez Alonso N, Mhatre S, \& Bechthold M (2018). Ceramic Morphologies. Precision and control in paste-based additive manufacturing. In ACADIA // 2018: Recalibration. On imprecisionand infidelity. [Proceedings of the 38th Annual Conference of the Association for Computer Aided Design in Architecture (ACADIA) ISBN 978-0-692-17729-7] Mexico City, Mexico 18-20 October, 2018, pp. 350-357. CUMINCAD. Accessed October 27, 2021 Retrieved from http://papers.cumincad.org/cgi-bin/works/paper/acadia18_ 350

10. AlOthman S, Im HC, Jung F, Bechthold M (2018) Spatial print trajectory: controlling material behavior with print speed, feed rate, and complex print path. In: In robotic fabrication in architecture, art and design 2018. Springer International Publishing, Cham, pp 167-180. https://doi.org/10.1007/978-3-319-92294-2_ 13

11. Seibold Z, Mhatre S, Alhadidi S, García del Castillo López JL, \& Bechthold M (2019). Janus Printing: Coextrusion based Multimaterial Additive Manufacturing for Ceramics. In ACADIA 19:UBIQUITY AND AUTONOMY [Proceedings of the 39th Annual Conference of the Association for Computer Aided Design in Architecture (ACADIA) ISBN 978-0-578-59179-7] (The University of Texas at Austin School of Architecture, Austin, Texas 21-26 October, 2019) pp. 576-585. CUMINCAD. Accessed October 27, 2021 Retrieved from http://papers.cumin cad.org/cgi-bin/works/paper/acadia19_576

12. Händle F (2007) Extrusion in ceramics. Springer, Berlin. https:// doi.org/10.1007/978-3-540-27102-4_2

13. Ugarte-Urzúa, J. P., Mhatre, S., Bechthold, M., \& Norman, S. (2020). Extruded Tessellations: A novel structural ceramic system at the intersection of industrial ceramic extrusion and CNC fabrication. In Blucher Design Proceedings (pp. 326-333). Presented at the Congreso SIGraDi 2020, Medellín, Colombia: Editora Blucher. https://doi.org/10.5151/sigradi2020-45

14. Overall S, Rysavy JP, Miller C, Sharples W, Sharples C, Kumar $S$ et al (2018) Made-to-measure: automated drawing and material craft. Technol Archit Des 2(2):172-185. https://doi.org/10.1080/ 24751448.2018.1497365
15. Seibold Z, Mesa O, Stavric M, Bechthold M (2018) Ceramic tectonics: tile grid Shell. Proc IASS Annual Symp 2018(8):1-8

16. Dorjpalam, S., Kawase, H., \& Yamaguchi, K. (2008). EXPERIMENTAL AND NUMERICAL STUDY ON DYNAMIC PROPERTIES OF FRICTION-RESISTANT DRY-MASONRY STRU CTURES. In 14th World Conference on Earthquake Engineering (第十四届国际地震工程会议) (p. A-X). 中国地震学会

17. Hubmer, P., \& Bscheider, E. (2015). MODULAR CERAMIC CONSTRUCTION SYSTEM (p. 12)

18. Bechthold M (2008) Innovative surface structures: technologies and applications. Taylor \& Francis, Abingdon, Oxon; New York

19. Alini L (2011) CCCloud Casalgrande Ceramic Cloud. Dalla produzione al progetto/CCCloud Casalgrande Ceramic Cloud. From production to project. Techne 1:130-137

20. Schodek D L, \& Bechthold M (2014). Structures (7th edition / Daniel L. Schodek, Martin Bechtold.). Boston: Pearson

21. Anderegg FO (1937) Super-ceramic building members*. J Am Ceram Soc 20(1-12):77-79. https://doi.org/10.1111/j.1151-2916. 1937.tb19865.x

22. Johnston RD, Chipman RD, Knapp WJ (1953) Prestressed ceramics as a structural material. J Am Ceram Soc 36(4):121-126. https://doi.org/10.1111/j.1151-2916.1953.tb12848.x

23. Shanley FR, Knapp WJ, \& Kurtz P Jr. (1966). An Investigation of Ceramics as Structural Materials (NASA Contractor Report No. NASA-CR-632) (p. 21). University of California. Retrieved from https://ntrs.nasa.gov/citations/19660029462

24. Devalapura RK, Krause GL, Sweeney SC, Littler D, Staab E (1997) Construction productivity advancement research (CPAR) program. In: Development of an innovative post-tensioning system for Prestressed clay brick masonry walls. CONSTRUCTION ENGINEERING RESEARCH LAB (ARMY), CHAMPAIGN Accessed October 27, 2021 Retrieved from https://apps.dtic.mil/ sti/citations/ADA327657

25. Wrana S, Cervenkova N, Miroslav K (2015). Green Vee System: Planted Ceramic Modular Load-Bearing System. In Proceedings of IASS Annual Symposia. Presented at the IASS Conference, Amsterdam

26. Brick masonry material properties (no. 3A). (1992) (p. 10). Accessed October 27, 2021 Retrieved from https://www.gobrick. com/docs/default-source/read-research-documents/technicalnotes/ 3a-brick-masonry-material-properties.pdf?sfvrsn $=0$

27. Rutten D (2013) Galapagos: on the logic and limitations of generic solvers. Archit Des 83(2):132-135. https://doi.org/10.1002/ad. 1568

28. Kalina RD, Lean SM, \& Breen JE (2011). Comparative Study of Mechanical and Corrosion Resistance Properties of Bridge PostTensioning Strands. Accessed October 27, 2021 Retrieved from https://trid.trb.org/view/1144043

29. McCool GE (2010). Evaluation of corrosion resistance of new and upcoming post-tensioning materials after long-term exposure testing (thesis). Accessed October 27, 2021 Retrieved from https:// repositories.lib.utexas.edu/handle/2152/ETD-UT-2010-12-2541

Publisher's note Springer Nature remains neutral with regard to jurisdictional claims in published maps and institutional affiliations. 